\title{
The representation of hydrological dynamical systems using Extended Petri Nets (EPN)
}

\author{
Marialaura Bancheri, ${ }^{1}$ Francesco Serafin ${ }^{2}$ and Riccardo Rigon ${ }^{2}$ \\ ${ }^{1}$ Institute for Mediterranean Agricultural and Forestry systems (ISAFOM), National Research Council \\ (CNR), Ercolano (NA), Italy \\ ${ }^{2}$ Department of Civil, Environmental and Mechanical Engineering, University of Trento, Tento, Italy
}

\section{Key Points:}

- We present a graphical system to represent hydrological dynamical systems called Extended Petri Nets (EPN).

- EPN have a one-to-one correspondence with the equations that drive systems.

- EPN topology and connections clarify the causal relationship between compartments and the feedback between them. Two different types of feedback are presented.

- EPN can be used to formalize perceptual models from field work into equations.

Corresponding author: Riccardo Rigon, riccardo.rigon@unitn.it 


\begin{abstract}
This work presents a new graphical system to represent hydrological dynamical models and their interactions. We propose an extended version of the Petri Nets mathematical modelling language, the Extended Petri Nets (EPN), which allows for an immediate translation from the graphics of the model to its mathematical representation in a clear way. We introduce the principal objects of the EPN representation (i.e. places, transitions, arcs, controllers and splitters) and their use in hydrological systems. We show how to cast hydrological models in EPN and how to complete their mathematical description using a dictionary for the symbols and an expression table for the flux equations. Thanks to the compositional property of EPN, we show how it is possible to represent either a single hydrological response unit or a complex catchment where multiple systems of equations are solved simultaneously. Finally, EPN can be used to describe complex earth system models that include feedback between the water, energy and carbon budgets. The representation of hydrological dynamical systems with EPN provides a clear visualization of the relations and feedback between subsystems, which can be studied with techniques introduced in non-linear systems theory and control theory.
\end{abstract}

\title{
1 Introduction
}

In the broad array of hydrological models (Beven, 2011; Wagener et al., 2004) an important category comprises those models that solve systems of Ordinary Differential Equations (ODEs) and their discrete counterparts (for an overview, please refer to Singh and Woolhiser (2002) and Kampf and Burges (2007)). This category includes lumped models, that is to say, models where spatial hydrological variability is integrated over single elements called Hydrological Response Units (HRUs): each HRU represents a certain sub-catchment, while the spatial organization of basins, if required at coarser scales, is obtained by connecting HRUs as nodes of a network. In this case, lumped models are also called "integral distributed models", (Todini, 1988). In each HRU, a model can treat the internal processes (runoff, evapotranspiration, root zone moisture, and so on) by using one or more ODEs. Therefore, integral distributed models are formed by systems of systems of ODEs.

Not all the aforementioned elements are present in all hydrological models, nor is the same nomenclature used. However, if we take as an example the models collected in the MARRMot 1.0 toolbox (Knoben et al., 2019), we have a substantial group (46) of the most widely used hydrological models, all of which solve ODEs. In literature, (Fenicia et al., 2008; Birkel et al., 2011; Hrachowitz et al., 2013), these Hydrological Dynamical Systems (henceforth HDSys) are used to interpret any of the hydrological processes from hillslope to catchment scale: they are ubiquitous.

The great variety of available models draws attention to the need to find some mathematical criterion for diagnosing their differences (e.g., Clark et al. (2008)). In this paper we suggest that associating an appropriate graphical-mathematical representation to each model can be a part of the diagnostic process.

Graphical representation has been fruitful in the sciences: the epitome is the case of Feynman diagrams in quantum electrodynamics (Kaiser, 2005), but representations of electrical circuits (Lohn \& Colombano, 1999), stock-flow diagrams of system dynamics models are also good examples (Takahashi, 2005) and reaction networks (Herajy \& Heiner, 2015; Baez \& Pollard, 2017) are also interesting examples. The resulting theories, informed by the diagrams, differed significantly from earlier approaches in the way the relevant phenomena were conceptualized and modelled. We believe that devising a graphical representation for hydrological models can also be fruitful, especially if the graphics are more than pictorial representations. As Oster, Perelson, and Katchalsky (1971) suggest, we seek a system where the dynamical equations can be read algorithmically 
from the graphs and diagrams, which are actually another notation for the equations themselves.

In hydrology we have great demands as we deal with various dynamical systems besides the water budget, such as the energy budget, the travel time transport of water, and the carbon cycle, to name a few. Therefore, the graphical representation developed should be expandable to more than one of the Earth system cycles; it should imply their mathematics; and it should help visualize their reciprocal feedbacks.

In our work, we want to complement the work presented, for instance, in Fenicia and Kavetski (2011) and in Clark et al. (2015). Those are papers with a large scope, and they treat very broad questions, from how to infer a model's structure using heuristic analyses of the functioning catchment (e.g., Butts, Payne, Kristensen, and Madsen (2004)) to the numerics used in sound, high-performance tools. With respect to the models addressed by those papers, the approach of this paper is agnostic: it does not explain how to build models but aims to present them in a clear way.

In summary, our paper tries to answer the following questions: is there a good way to graphically represent budgets (water, energy and other) that gives a clear idea of the type of interactions they are subject to before seeing the equations? Where in a graphical representation can information about fluxes and parameters be optimally placed? Can we obtain a graphic language that corresponds to mathematics in a strict and univocal manner? Can the graphical representation help translate the perceptual models derived from field work into mathematics and equations? Can we visually represent the feedbacks between hydrology and ecosystems?

\section{Examples of graphical representation of hydrological models}

To expound what was said in the Introduction, we reproduce here figures representing some well known hydrological models.

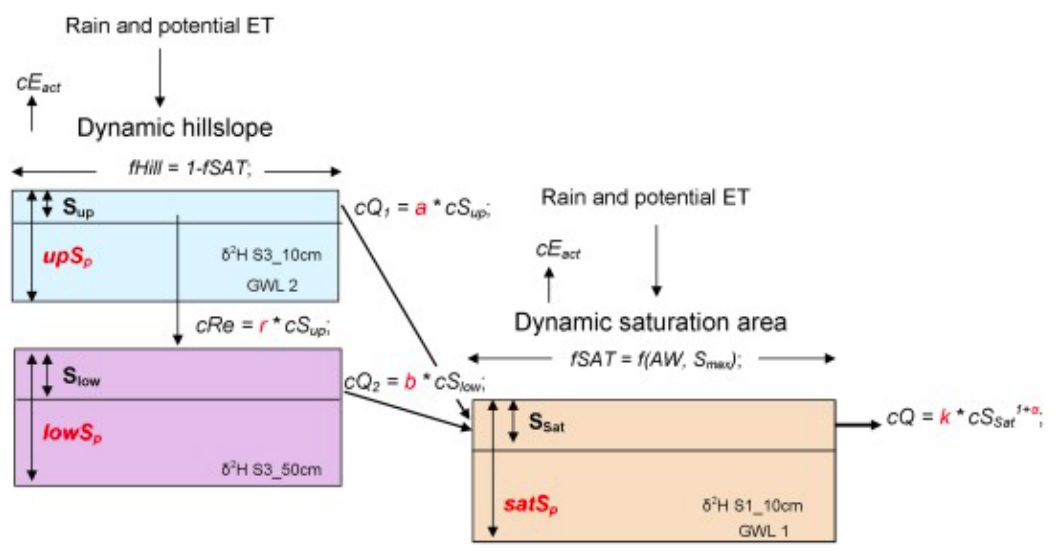

Figure 1. Representation of the model proposed in Birkel et al., (2011). The figure is adapted from Soulsby et al. (2016)

Figure 1 shows a schematic representation of the model proposed in Birkel et al. (2011), which we shall refer to as the BST model (after Birkel, Soulsby, Tetzlaff). In the graphic, the relationships between different BST parts are clear; this is not true for the fluxes, which have their mathematical expressions annotated in the graphic. Computer 


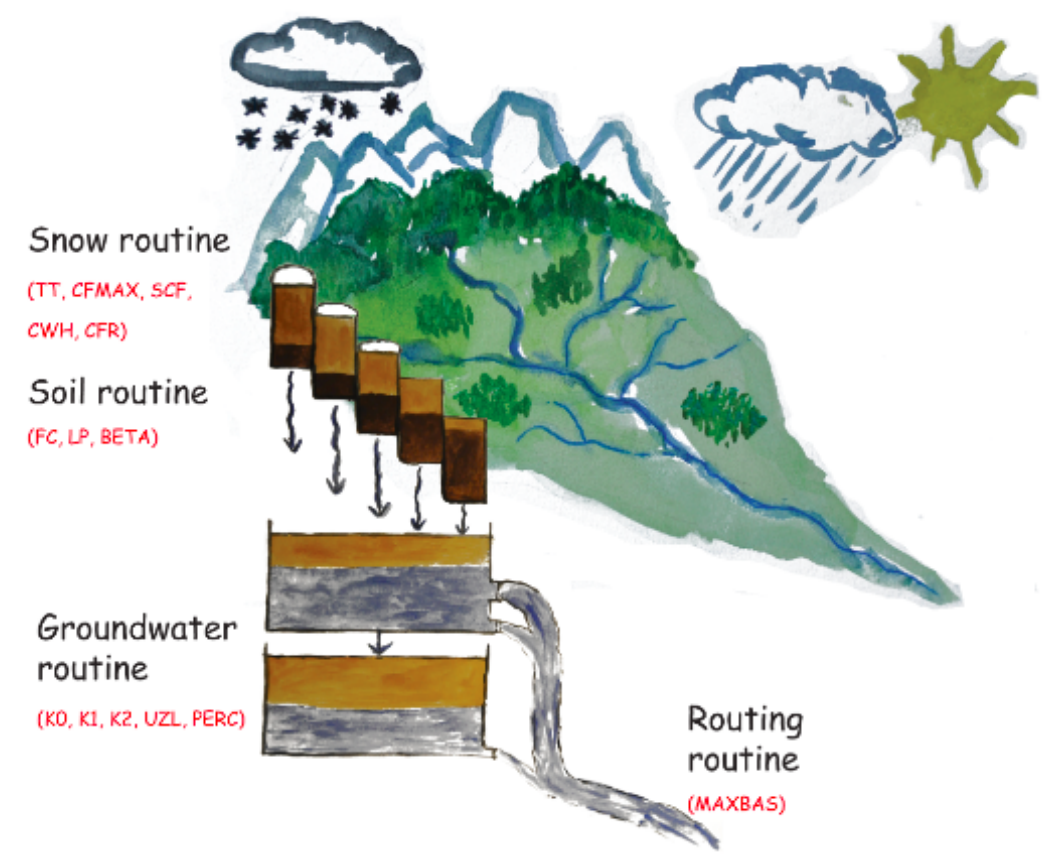

Figure 2. Hydrologiska Byråns Vattenbalansavdelning (HBV) model as illustrated in Seibert and Vis (2012)

scientists would say that the figure has been given too many responsibilities and too much information, resulting in a cluttered graphic. To understand and reproduce the BST model, decryption work is required in a back and forth process between the image and the text. This process is probably unavoidable in all cases, but the reading can be made easier by referring to standard places in the manuscript.

Figure 2 refers to the Hydrologiska Byråns Vattenbalansavdelning (HBV), adapted from Seibert and Vis (2012), a standard reference for HBV. Those Authors opted for a pictorial representation that cannot be considered very explicative from a mathematical point of view, as it serves to identify the compartments of Earth surface involved. While the Figure is very effective in providing an immediate association between the model components and their natural counterparts, the interested reader must, however, peruse other papers to get all the information needed to understand the workings of the HBV model.

Figure 3, adapted from Hrachowitz et al. (2013), is one of three model structures used in a heuristic procedure (Fenicia et al., 2008) to assess catchment behaviors. The figure conveys a lot, but details about flux partition remain unclear. Single reservoirs need to act like two or three reservoirs, as represented by the use of different colours. The (inattentive) reader could be easily confounded to see only four reservoirs in this model, when, instead, the $S_{U}$ reservoir should be split in two, and some others are missing too, as we shall see later.

The model representations in Figures (1) to (3) keep some elements fixed, namely, the reservoirs and the arrows. Others elements vary, and some are discarded, in accordance with the Authors' views. That is to say, it is not possible to gather the main information at a glance or, rather, there is no common understanding of what the main information to be conveyed is. We cannot easily see the similarities between models, and the style changes in representation make any understanding even more difficult. 
(b) Loch Ard - Burn 11

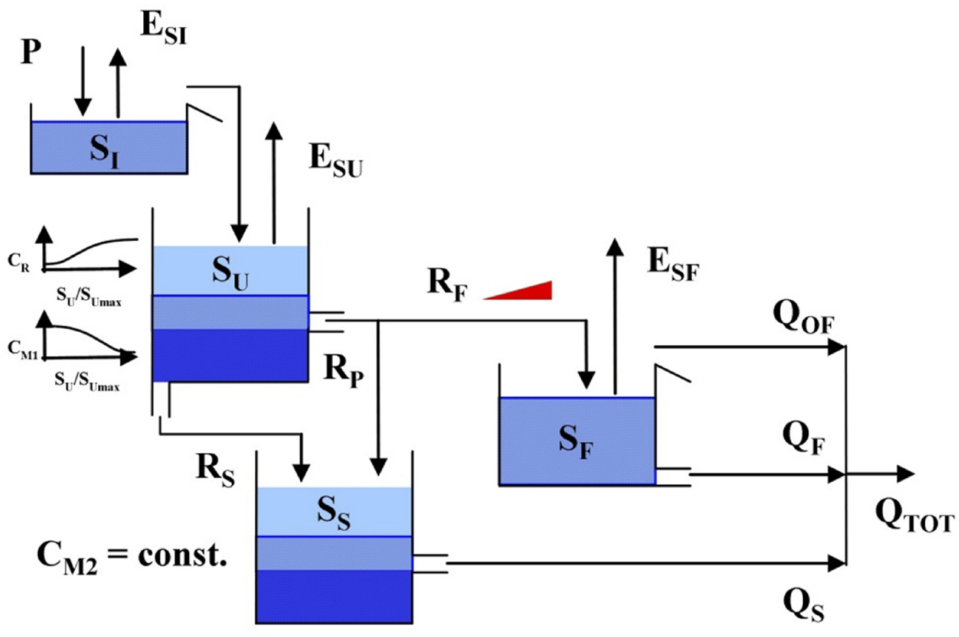

(d) $\mathrm{C}_{\underline{M, \text { dyn }}}$

Figure 3. Representation of one of the models proposed in Hrachowitz et al. (2013), here called the Ard-Burn model

The goal of this paper is to bring order to HDSys representations by building an algebra of graphical objects where any symbol will correspond to a mathematical term or group of terms. The main information to be communicated is the number of equations that a model uses and the number of input and output fluxes present for each equation. At the same time, the number and location of model parameters should be clear, but, in our opinion, need not be communicated directly by the graphics.

\section{Principal graphical objects in Extended Petri Networks}

Among the various possible graphic representation, we find that the Petri Nets (PN) are particularly suited to our scope. PN are a mathematical modelling language for the description of distributed systems. The concept was originally presented in Carl Adam Petri's dissertation (Petri, 1966) and their early development and applications are found in reports that date back to the 1970 s. PN became popular in theoretical computer science (Jensen \& Kristensen, 2009), biology (Koch, 2010; Koch et al., 2010; Wilkinson, 2011), especially to represent parallel or concurrent activities (Murata, 1989), stochastic mechanics (Baez \& Biamonte, 2012; Haas, 2006; Marsan et al., 1994) and to describe reaction networks (Gilbert \& Heiner, 2006; Herajy \& Heiner, 2015). In the case of reaction networks, clearly treated in Herajy and Heiner (2015), there are specific rules for computation, which are implicit in the PN structure used, that do not lead to correct mass and energy budget equations. This matter is referred to in more detail in the supplementary material of this paper.

Initially, PN were used to model discrete time processes managing discrete, numerable quantities. However, HDSys require a time-dependent form of PN. Such a form is already present in literature, (Ramchandani, 1974; Merlin \& Farber, 1976; Berthomieu \& Diaz, 1991; Champagnat et al., 1998; Alla \& David, 1998) and is usually called "Time Continuous Petri Nets". These are the generalization of discrete processes that are approximated as continuous ones (Silva \& Recalde, 2004). However in HDSys, we mostly deal with systems of ODEs, where the equations are usually non-linear and the state vari- 

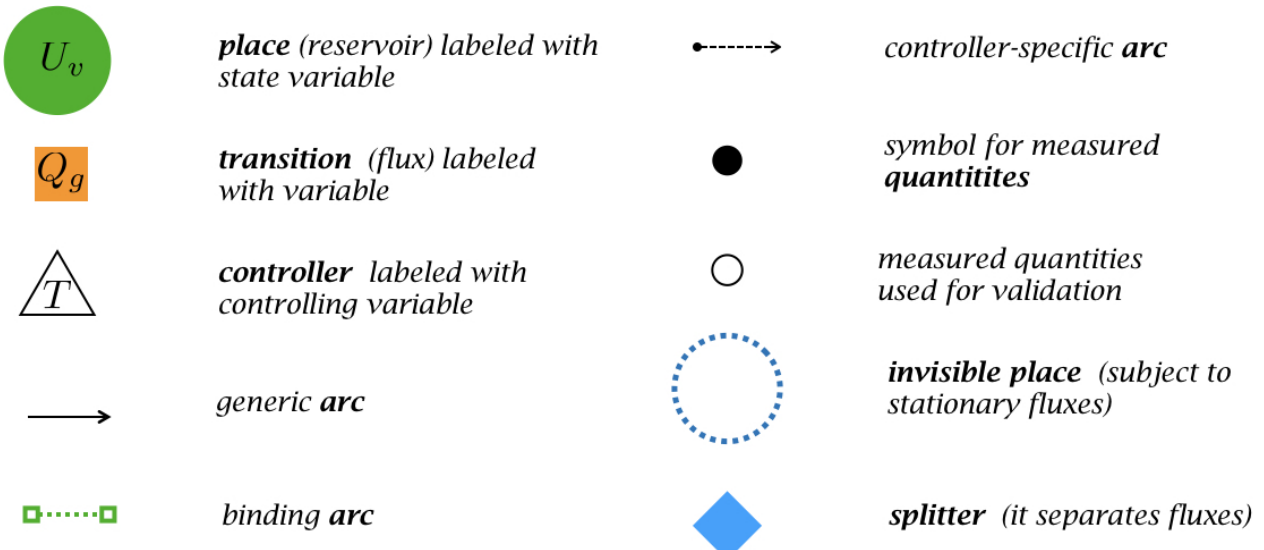

Figure 4. The graphical objects used in EPN. Not all of them need to be present.

ables are inherently continuous (mass, energy and momentum of water or other substances). Thus we required a different type of PN that we have called Extended Petri Nets (EPN), with different rules from, for example, the reaction networks or other typologies of PN.

When looking at PN, hydrologists must adjust their interpretative habits: reservoirs (now called places) are represented as circles, and fluxes (now called transitions) between reservoirs (or places) are represented as squares. To distinguish between different places, the graphical objects can be colored; conventionally, we use the same color for places and transitions describing the same compartment, such as, for instance, the soil or root zone as distinct from the groundwater zone. The graphical objects have enough space for the symbol of the variable they deal with, as shown in Figure 4. A third group of objects are the controllers (represented by a triangle). They are quantities that affect fluxes but are not fluxes themselves. Their value can depend on one or more state variables, i.e. on places, and they are in charge of regulating fluxes. As an example of a controller, consider a mass flux, $Q$, proportional to the storage, $S$, such that $Q=k S$. If $k=k(T)$, where $T$ is the temperature, then $T$ is a controller of the flux.

The connection between places and transitions is shown with an arc; arcs between two places (reservoirs) or between two transitions (fluxes) are not allowed. As shown in Figure 4, arcs can be drawn in different ways to convey more detail: if they carry a linear flux they are generic and do not include any symbols; if the carry a non-linear flux, they are marked by a coloured bullet. Binding arcs are used when two different fluxes in two different budgets contain the same variable. That is to say, they join two transitions that contain the same variable for graphical reasons, such as, for example, evapotranspiration in the water and energy budgets, as shown in section 7 . Oriented dashed arcs show connections from places to controllers and from controllers to transitions. Connections between places and transitions that pass trough controllers only affect the expression of fluxes but do not alter the number of equations. Any oriented arc also represents a causal relation between the originating entity and the receiving one: upstream quantities can be thought to cause downstream ones. Therefore the controllers show the causal relationship between state variables and fluxes, which would otherwise be hidden graphically. For this reason we call the wiring from places to controllers to transitions hidden wiring or $\mathbf{h}$-wiring, while the wiring that connects directly between places and transitions is called flux wiring or f-wiring.

In Figure 4 we also introduce a small, solid, black circle, which is used to mark a measured quantity, i.e. a quantity that is given as known input and drives the simulation. The most common example of known input is precipitation, which is usually ob- 
tained from ground measurements or other sources. The small, empty circle represents a quantity that is also given but is used to assess the goodness of the model. In hydrology, the typical case is the discharge, which is an output of the models and whose measured values are used for validation. The big circle with the dotted border represents instead a hidden place whose budget is stationary, as it returns all the mass it takes in. A typical example in hydrological models is that of uphill surface waters and groundwaters summing to give the total surface discharge.

All the allowable connections between EPN objects are represented in Figure 5; no other type of connection is possible. A transition can be connected to more than one place, implying the existence of a partition coefficient, represented by a splitter (the diamond symbol in Figure 4). For instance, the total amount of precipitation can be divided into snowfall and rainfall, or between two reservoirs representing surface waters and the root zone. In those cases the splitter represents the need for some rule to separate the fluxes. Figure 5 shows a splitter in action, where precipitation $J$ is divided into 2 components, $J_{u p}$ and $J_{\text {down }}$. In the case presented in section 4.1, the separation is simply obtained with a partition coefficient, for which $\alpha$ part of the precipitation goes into a surface reservoir and $(1-\alpha)$ part goes to a soil reservoir. Usually, however, each internal transition is connected to only one place. Similarly, a place can be connected to more than one transition, also implying a partitioning rule or coefficient. Two places cannot be connected to a unique transition, and this marks a substantial difference with reaction networks (Gilbert \& Heiner, 2006), as shown in detail in the supplementary material of this paper.

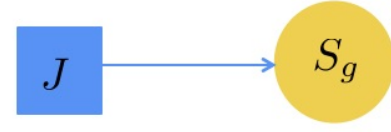

transition to place connection (input to place)

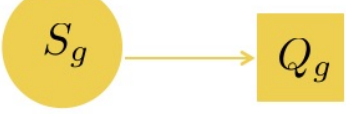

place to transition connection (output from place)

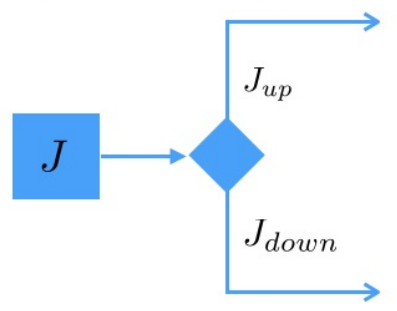

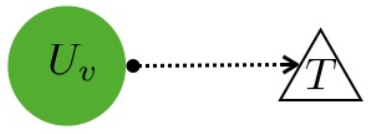

place affecting a controller. Meaning that $T$ is a function of $U_{v}$

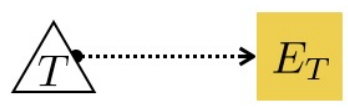

controller affecting a transition (flux). Meaning that parameters in $E_{T}$ are a function of $T$

\section{a splitter separating flux J into two contributions}

Figure 5. Allowed connectivity between places, transitions and controllers, and a splitter in action. No other type of connection is possible.

To obtain the required budget equations, each place depicted in Figures 4 and 5 must correspond to the time variation of the quantity indicated in it. For instance, the green place marked $U_{v}$ represents the following part of a conservation equation:

$$
\frac{d U_{v}}{d t}
$$


with the quantity $U_{v}$ being, for instance, the internal energy of a compartment of the HDSys. The differential operator can be changed for other operators, depending on the type of equation we are writing, and, therefore a table defining which differential operator we are using is needed. From these rules we can represent a simple linear reservoir, as shown in Figure 6 on the left.

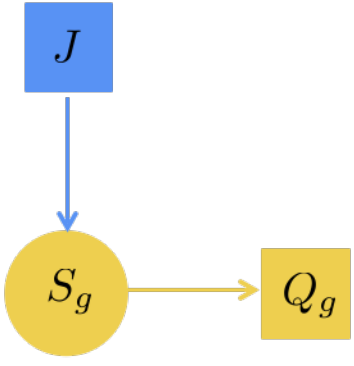

a linear system (reservoir)
represented

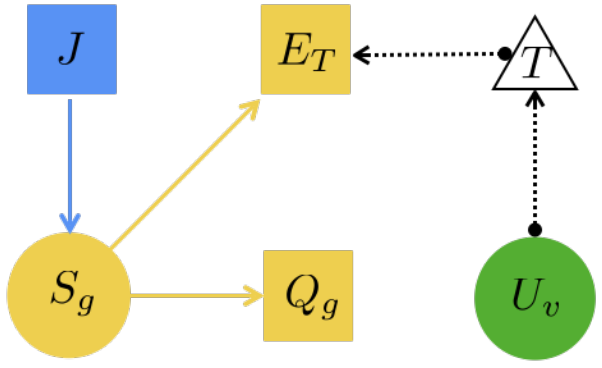

a system whose $E_{T}$ is controlled (also) by $U_{v}$ via $T$

Figure 6. A simple linear reservoir (on the left) and a more complex example (on the right).

In Figure 6 the flux $J$ enters the place $S_{G}$, while the flux $Q_{G}$ exits the same place. Therefore the budget is read as:

$$
\frac{d S_{g}}{d t}=J(t)-Q_{g}(t)
$$

Introducing another outgoing flux into the system, as shown on the right in Figure 6, the equation is modified to:

$$
\frac{d S_{g}}{d t}=J(t)-Q_{g}(t)-E_{T}(t)
$$

The action of the controller $T$ on $E_{T}$ remains hidden until we specify the mathematical form of the fluxes (transitions). This will be shown with the reference cases in the next section and mathematically formalized in section 8 .

\section{Casting the BST, HBV and Ard-Burn models into the EPN repre- sentation}

Applying the rules introduced in section 3, we can now represent the three models of section 2 using EPN. We will present the details for the BST model, while we will be more concise for the others.

\subsection{The BST model}

As a result of the rules introduced in Section 3, the BST model, shown in Figure 1, can be represented using EPN as shown in Figure 7. It shows three coupled ODEs, represented by three places, colored light blue, orange and dark red (colors chosen to be colorblind friendly, as better explained in the supplementary material). The small black bullets indicate quantities that should be measured and, therefore, assigned externally. A fourth, unnamed place has been added to highlight that measured data refers to the total flux, $Q_{T}=Q_{\text {sat }}+Q_{\text {low }}$, and not the two fluxes separately. This place is, in a sense, 


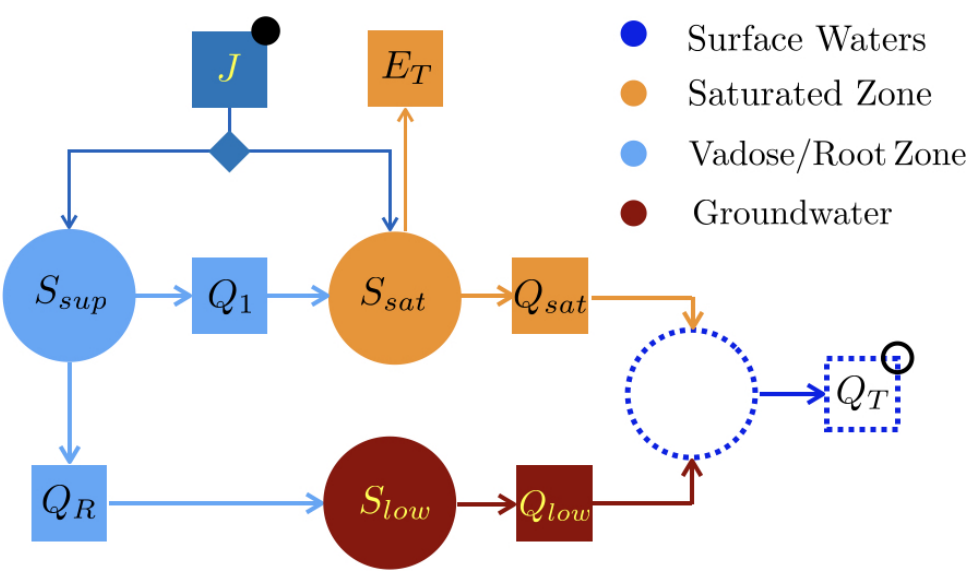

Figure 7. Representation of the BST model (Birkel et al., 2011) using EPN. Compared with the original representation of Figure 1, this Figure contains less information, however, it is sufficient to write down the mass conservation equations for the system. The invisible reservoir is unnamed, since it is just the sum of $Q_{l o w}$ and $Q_{\text {sat }}$ and does not store water. As the legend shows, each color refers to a different conceptual-physical compartment through which the water flows. The outcomes from the splitter are named according to Table 1.

invisible because it does not introduce any ODE and its storage variation is always null; it has been left nameless and shown with dashed borders to reinforce this concept.

From the graph in Figure 7, the ruling equations are easily written as:

$$
\frac{d S_{\text {sup }}(t)}{d t}=\underbrace{\alpha J(t)}_{J_{l}}-Q_{1}(t)-Q_{R}(t)
$$

for the "sup" storage;

$$
\frac{d S_{s a t}(t)}{d t}=\underbrace{(1-\alpha) J(t)}_{J_{r}}+Q_{1}(t)-Q_{s a t}(t)-E_{T}(t)
$$

for the "sat" storage; and

$$
\frac{d S_{l o w}(t)}{d t}=Q_{R}(t)-Q_{\text {low }}(t)
$$

for the "low" storage.

Finally

$$
0=Q_{T}(t)-Q_{\text {low }}(t)-Q_{\text {sat }}(t)
$$

In the BST model, there is one given (measured) input, precipitation $J$, which splits into $J_{l}$ and $J_{r}$, and one given output, $Q_{T}$, each of which is marked with a small circle in Figure 7. One of the equations (the "orange" one, Eq. 5) contains a non-linear term, while the others are linear. Figure 7 is not sufficient to implement the model because its role (responsibility) is to identify the number of equations and to allow the reader to write the water budgets with unspecified fluxes. For complete information, two other elements are needed:

- a dictionary giving the names of the symbols in the graphic (conveying their meaning), given in Table 1; and 
- an expression table giving mathematical completeness to the fluxes, presented in Table 2 . When there is a splitter, the corresponding flux is duplicated as necessary.

Expressions for places are not reported here since, by default, they associate any variable $S_{*}$ to its time derivative $d S_{*} / d t$. However, in the most complex cases it is required to report them. Because the specification of fluxes usually introduces new variables, an extension to the dictionary may be necessary after writing the expression table. The substitution of the expressions in Table 2 into equations 4 to 7 gives the set of equations necessary to fully reproduce the model.

Table 1. Full dictionary associated to the EPN representation of the BST model (Birkel et al., 2011). $P$ stands for "parameter", $F$ for "flux", $S V$ for "state variable", $V$ for "variable". [T] stands for time units, $[\mathrm{L}]$ for length units, $[E]$ for energy units. It contains the symbols present in Figure 7 and also those implied by Table 2

\begin{tabular}{llll}
\hline Symbol & Name & Type & Unit \\
\hline$a$ & linear reservoir coefficient & $\mathrm{P}$ & {$\left[T^{-1}\right]$} \\
$b$ & non-linear reservoir coefficient & $\mathrm{P}$ & {$\left[T^{-1}\right]$} \\
$c$ & non-linear reservoir exponent & $\mathrm{P}$ & {$[-]$} \\
$d$ & linear reservoir coefficient & $\mathrm{P}$ & {$\left[T^{-1}\right]$} \\
$e$ & linear reservoir coefficient & $\mathrm{P}$ & {$\left[T^{-1}\right]$} \\
$f$ & dimensional ET coefficient & $\mathrm{P}$ & {$\left[E^{-1} L^{5}\right]$} \\
$E_{T}(t)$ & evapotranspiration & $\mathrm{F}$ & {$\left[L^{3} T^{-1}\right]$} \\
$J^{\bullet}(t)$ & precipitation rate & $\mathrm{F}$ & {$\left[L^{3} T^{-1}\right]$} \\
$J_{l}(t)$ & precipitation rate going into $S_{\text {sup }}$ & $\mathrm{F}$ & {$\left[L^{3} T^{-1}\right]$} \\
$J_{r}(t)$ & precipitation rate going into $S_{\text {sat }}$ & $\mathrm{F}$ & {$\left[L^{3} T^{-1}\right]$} \\
$Q_{1}(t)$ & discharge from the upper reservoir & $\mathrm{F}$ & {$\left[L^{3} T^{-1}\right]$} \\
$Q_{\text {low }}(t)$ & discharge from the lower reservoir & $\mathrm{F}$ & {$\left[L^{3} T^{-1}\right]$} \\
$Q_{\text {sat }}(t)$ & discharge from the saturated reservoir & $\mathrm{F}$ & {$\left[L^{3} T^{-1}\right]$} \\
$Q_{R}(t)$ & recharge term of the lower reservoir & $\mathrm{F}$ & {$\left[L^{3} T^{-1}\right]$} \\
$Q_{T}^{o}(T)$ & total discharge at the outlet & $\mathrm{F}$ & {$\left[L^{3} T^{-1}\right]$} \\
$R_{n}(t)$ & net radiation & $\mathrm{F}$ & {$\left[E L^{-2} T^{-1}\right]$} \\
$S_{\text {low }}(t)$ & storage in the lower reservoir & $\mathrm{SV}$ & {$\left[L^{3}\right]$} \\
$S_{\text {max }}(t)$ & maximum storage in the saturated reservoir & $\mathrm{SV}$ & {$\left[L^{3}\right]$} \\
$S_{\text {sat }}(t)$ & storage in the saturated reservoir & $\mathrm{SV}$ & {$\left[L^{3}\right]$} \\
$S_{\text {sup }}(t)$ & storage in the upper reservoir & $\mathrm{SV}$ & {$\left[L^{3}\right]$} \\
$t$ & time & $\mathrm{V}$ & {$[\mathrm{T}]$} \\
$\alpha$ & partitioning coefficient & $\mathrm{P}$ & {$[-]$} \\
\hline
\end{tabular}

Table 2 clarifies the parameters of the model:

- $J(t)$ is an external measured quantity (thus it is marked with a bullet, $\bullet$ );

- Only five parameters $(a, b, c, d, e)$ are necessary since $E_{T}$ is also assumed measured (as per original paper).

\subsection{The HBV model}

As another example, let us consider the EPN representation of the HBV model, shown in Figure 8. The HBV model was first shown in Figure 2 in Section 2. Tables A.1 and A.2 in Appendix A contain the associated dictionary and expression table. 
Table 2. Expression table associated to the EPN representation of the BST model(Birkel et al., 2011). Quantities marked with bullets represent measured quantities.

\begin{tabular}{lll}
\hline Flux & Name & Expression \\
\hline$E T(t)$ & evapotranspiration & $E T(t)$ \\
$J^{\bullet}(t)$ & precipitation rate & $\bullet$ \\
$J_{l}(t)$ & precipitation rate going into $S_{\text {sup }}$ & $\alpha J^{\bullet}(t)$ \\
$J_{r}(t)$ & precipitation rate going into $S_{\text {sat }}$ & $(1-\alpha) J^{\bullet}(t)$ \\
$Q_{\text {up }}(t)$ & discharge from the upper reservoir & $a S_{\text {sup }}(t)$ \\
$Q_{\text {low }}(t)$ & discharge from the lower reservoir & $d S_{\text {low }}(t)$ \\
$Q_{\text {sat }}(t)$ & discharge from the saturated reservoir & $b S_{\text {sat }}(t)^{c}$ \\
$Q_{R}(t)$ & recharge term of the lower reservoir & $e S_{\text {up }}(t)$ \\
$Q_{T}^{o}(t)$ & total discharge at the outlet & $Q_{\text {sat }}+Q_{\text {low }}$ \\
\hline
\end{tabular}

The HBV model identifies four major compartments, snow (red), soil (yellow), groundwater (cyan) and surface waters (bright blue), as well as precipitation. It contains six ODEs and, in contrast with the BST, it also contains a loop between $S W E$ (snow water equivalent) and $W_{s}$ (liquid water in snow). This loop implies that the output of liquid water from snow can refreeze and increase the amount the snow water equivalent from which melted water derives and, by definition, adds a feedback to the system. This causes some complications for the resolution of the model at the numerical level. In fact, parts of graphs within loops have to be solved simultaneously with an iterative method (Carrera et al., 2005; Patten et al., 1990), which usually requires an overhead in computation proportional to the number of elements in the loop.

A new feature appearing in the HBV model representation is the introduction of a controller. The triangle marked with $T$ shows explicitly that temperature controls various fluxes, as made clear in Expression Table A.2: Actual Evapotranspiration, $E_{\text {act }}$, precipitation, $P$, melting rate of snow, $M$, and refreezing rate of the liquid water in the snowpack, $R$, are all controlled by temperature. For illustrative purposes, a fictitious dependence of $T$ on $S_{\text {soil }}$ has been added, with the scope of introducing controller dependent loops, which will be detailed in section 8 .

\subsection{The Loch Ard-Burn model}

Finally, Figure 9 represents the Loch Ard-Burn model in Hrachowitz et al. (2013), i.e. the model first shown in Figure 3 of Secton 2. The model has four major compartments: interception by vegetation (in green), an unsaturated reservoir (dark orange), a fast reservoir (light blue), a slow reservoir (dark blue). In this case we, the Authors, have preferred to identify the compartments with process names rather than locations and, in a sense, this is also the choice in the perceptual model of the catchment. Compared to the original representation, we have added three new reservoirs: the invisible $S_{O}$, and $X_{F}$ and $X_{S} . S_{O}$ makes sense of the fluxes $R_{p}$ and $R_{s}$ that otherwise would both go from $S_{S U}$ into $S_{S}$ without identifying them properly. In fact, the use of different kinds of blue in the original representation in Figure 3 implies the existence of this reservoir. Hrachowitz et al. (2013) introduced it to adjust the simulated water age to that measured with tracers. $S_{O}$ does not accumulate water, implying that $R_{S}=R_{O}$, with a null net water budget exchange between $S_{O}$ and $S_{S U}$ reservoirs, but it mixes the younger water of the upper reservoirs with older waters to get the right water age at the budget. This trick was used before in (Fenicia et al., 2010) and we shall not discuss it fully here.

In Hrachowitz et al. (2013) the discharges $R_{F}$ and $R_{P}$ from the unsaturated reservoirs seem to go to reservoirs $S_{F}$ and $S_{S}$. However, these actually receive inputs $R_{F}^{*}$ and 


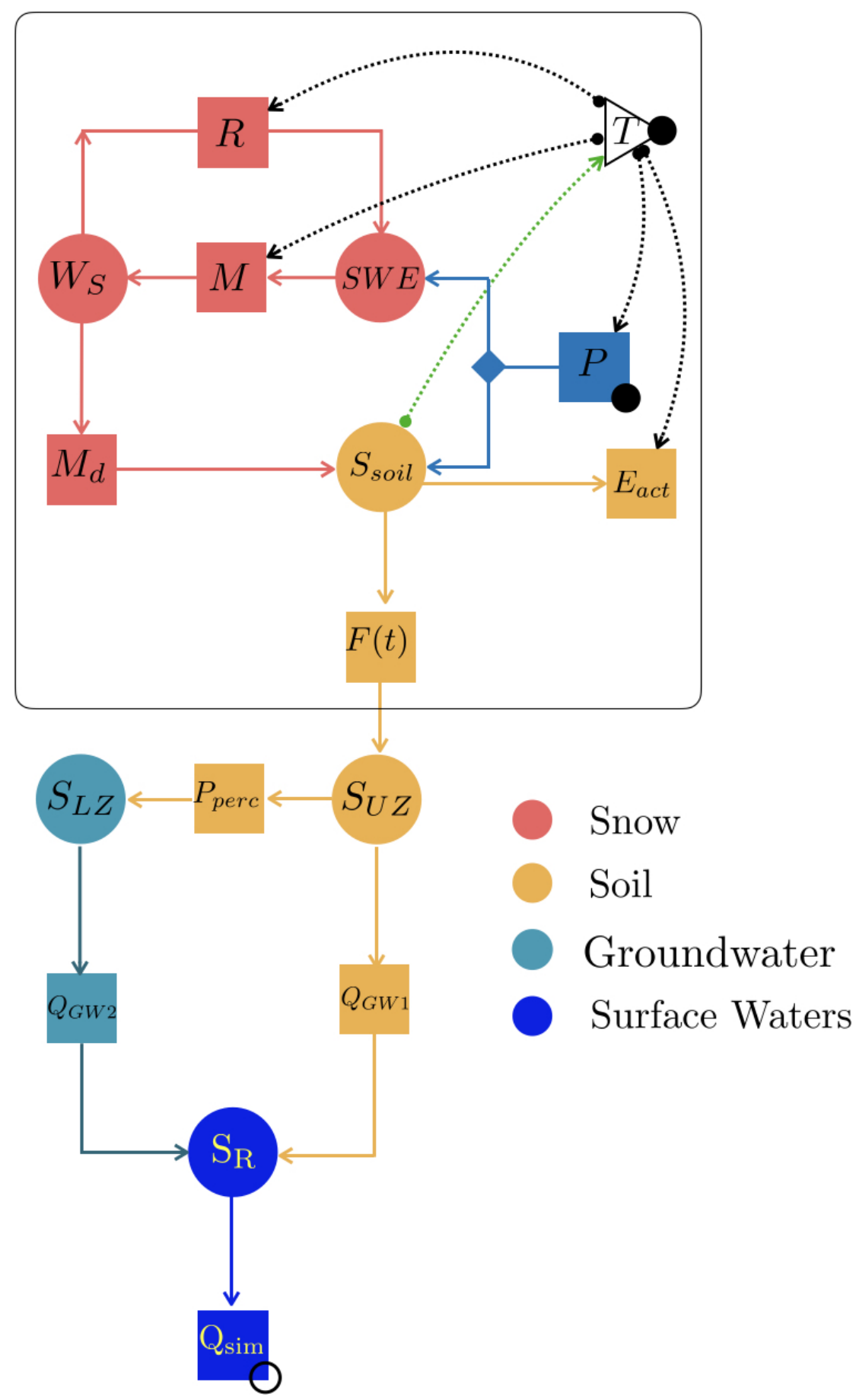

Figure 8. Representation of the HBV model in (Seibert \& Vis, 2012). It contains six reservoirs - ODEs - and an external controller of various fluxes, the temperature $T$. The black bullets indicate that $P, T$ and $Q_{\text {sim }}$ are measured quantities: $T$ and $P$ are used for running the model, while $Q_{\text {sim }}$ is usually used for calibration/validation. For the meaning of the symbols, please refer to the dictionary in Table A.1.

$R_{P}^{*}$, which are the result of a convolution of $R_{F}$ and $R_{P}$ with some unit hydrographs. All of this implies the existence of additional reservoirs (places) to accommodate a wa- 
ter budget. For example, the discharges $R_{F}$ and $R_{F}^{*}$ are associated to the budget:

$$
\frac{d X_{F}}{d t}=R_{F}-R_{F}^{*}
$$

where the expression of the discharges is given in Table B.1 in Appendix B. In particular:

$$
R_{F}^{*}=\int_{0}^{t} h_{F}\left(t-t_{i n}\right) R_{F}\left(t_{i n}\right) d t_{i n}
$$

where $h_{f}$ is a instantaneous unit hydrograph whose expression is:

$$
h_{F}(t)= \begin{cases}1 / 2 t / T_{F}^{2} & 0<t<T_{F} \\ 0 & \text { otherwise }\end{cases}
$$

where $t$ is time and $T_{F}$ is a suitable parameter.

One might question whether this is the simplest modelling structure accounting for tracer measurements and whether the place $S_{S O}$ is necessary to have proper water ages at the outlet. We merely observe that the representation in Figure 9 explicits this more clearly than Figure 3. Besides, Figure 3 ignores the existence of the discharge $R_{U}$, which is necessary to preserve the mass budget of the unsaturated reservoir $S_{S U}$. It is worth noting how the inclusion of controllers in the EPN representation shows clearly the importance of potential evapotranspiration $E_{p}$ and the $C_{E}$ parameter (a function of storages $S_{S U}$ and $S_{F}$ ) on evapotranspiration; otherwise, this would only be apparent by a careful inspection of the flux expressions. The Dictionary and Tables for the Ard-Burn model are presented in Appendix B.

\section{Use of Petri Nets for interpreting field work}

EPN can be used during the "perceptual phase" of research that moves from experimental evidence to the construction of an appropriate numerical model of a catchment. This can be done either according to the strategies defined in Fenicia and Kavetski (2011) and Clark et al. (2015), or with a more qualitative procedure, like the one we follow here, which represents just one practical application of EPN's functionalities. As an example, we can take the description of the Maimai catchment (Gabrielli et al., 2018), which is probably among the most widely studied small catchments in the world. The dynamics of the catchment is described as: "Catchment storage is formed by two sharply contrasting and distinct hydrological units: shallow, young soil storage, and deep, much older bedrock groundwater". Therefore, there are at least two storage reservoirs. The description then continues: "This storage pairing produces a bimodal, seasonal streamwater". This means that streams are a third reservoir that collect water from the other two, the soil and groundwater reservoirs. It then states that during the summer months there is evapotranspiration, $E_{T}$, and that it is an important term of the water budget. In a conceptual model $E_{T}$ can only come from the soil reservoir. The groundwater reservoir contributes to surface waters and downstream storage. A proper description of the catchment should also include the effects of interception and evaporation from the canopy; however, for simplicity, these are not taken into account here.

From this description, then, it seems that the perceptual model can be instantiated with two EPN places, which correspond to a set of two main ordinary differential equations, as shown in Figure 10. Because of its similarity with the system proposed by Kirchner (2016), we have used the names introduced in that paper, with the exception of evapotranspiration, $E_{T_{s}}$, and percolation, $R_{l}$, which we have added.

Another reservoir can be added to account for surface water storage where groundwater and soil water mix. This reservoir is where the fluxes $\breve{L}$ and $Q_{l}$ are summed and, as such, it is an invisible place. The dictionary for this system is presented in Table 3 . 

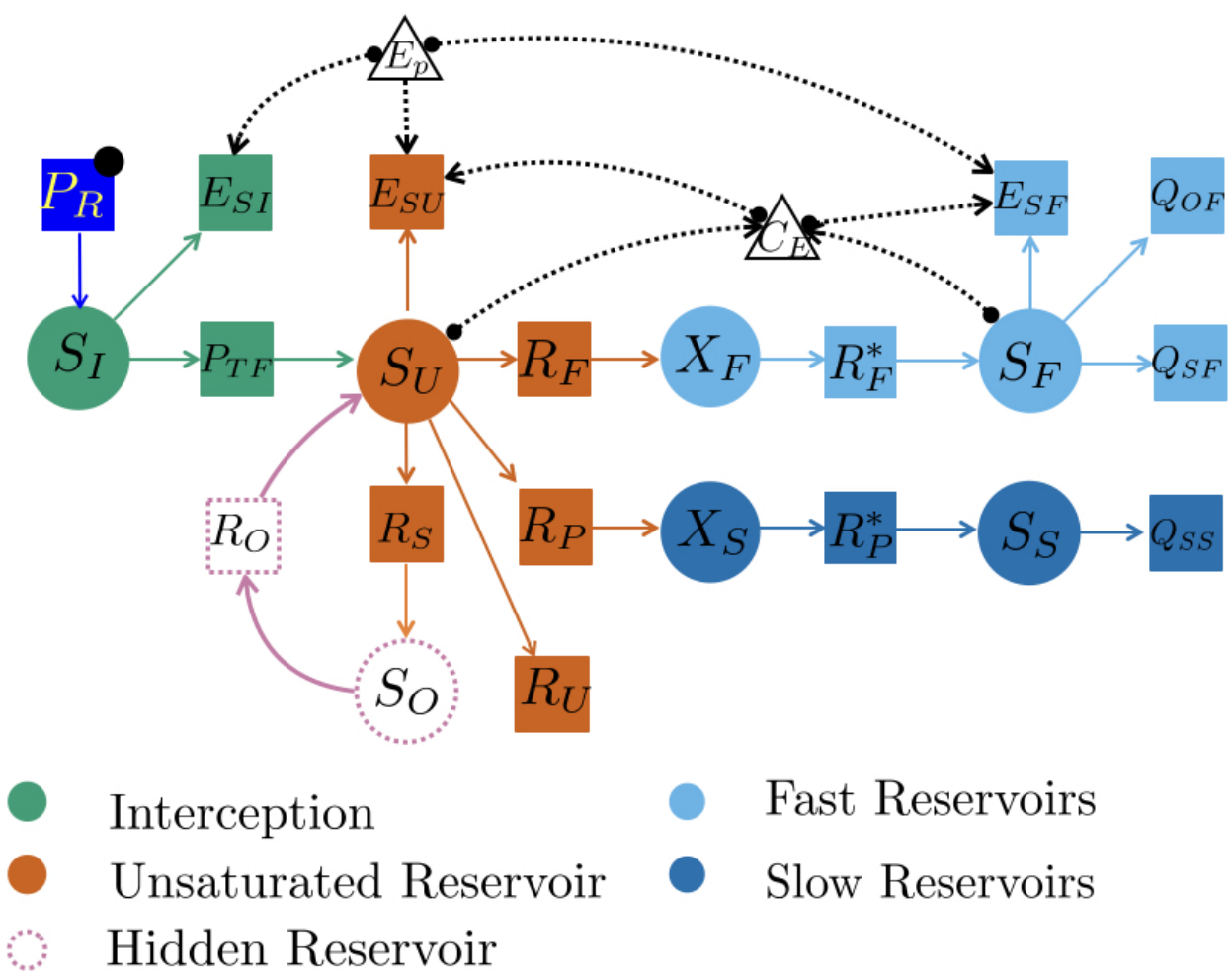

Figure 9. EPN representation of the Ard-Burn model, corrected for proper water age tracking. It has seven main water budget equations, derived from an accurate reading of Hrachowitz et al. (2013). The red dotted reservoir, $S_{O}$, is added to account properly for tracer history. The bluish reservoirs account for lag times from $S_{S U} \rightarrow S_{F}$ and $S_{S U} \rightarrow S_{S}$.

Table 3. Dictionary for the Maimai catchment model. $F$ indicates "flux"; $S V$ "state variable"; $V$ "variable". Quantities marked with bullets represent measured quantities.

\begin{tabular}{llll}
\hline Symbol & Name & Type & Units \\
\hline$E_{T_{s}}(t)$ & Evapotranspiration from the soil reservoir & $\mathrm{F}$ & {$\left[\mathrm{L} \mathrm{T}^{-1}\right]$} \\
$L(t)$ & Discharge from soil & $\mathrm{F}$ & {$\left[\mathrm{L} \mathrm{T}^{-1}\right]$} \\
$\hat{L}(t)$ & Recharge to groundwater & $\mathrm{F}$ & {$\left[\mathrm{L} \mathrm{T}^{-1}\right]$} \\
$P^{\bullet}(t)$ & Precipitation & $\mathrm{F}$ & {$\left[\mathrm{L} \mathrm{T}^{-1}\right]$} \\
$Q_{l}(t)$ & Discharge from groundwater & $\mathrm{F}$ & {$\left[\mathrm{L} \mathrm{T}^{-1}\right]$} \\
$Q_{S}^{o}(t)$ & Total discharge & $\mathrm{F}$ & {$\left[\mathrm{L} \mathrm{T}^{-1}\right]$} \\
$R_{l}(t)$ & Percolation to a deeper aquifer & $\mathrm{F}$ & {$\left[\mathrm{L} \mathrm{T}^{-1}\right]$} \\
$S_{l}(t)$ & Storage in the groundwater reservoir & $\mathrm{SV}$ & {$[\mathrm{L}]$} \\
$S_{u}(t)$ & Storage in the soil reservoir & $\mathrm{SV}$ & {$[\mathrm{L}]$} \\
$t$ & time & $\mathrm{V}$ & {$[\mathrm{T}]$} \\
\hline
\end{tabular}

To understand how to write the tentative equations for such a system, we need to further clarify the semantics of the graph, i.e. we need to make the mathematical structure of the fluxes explicit. For this one can find inspiration in Kirchner (2016) but we do not pursue it further here. 


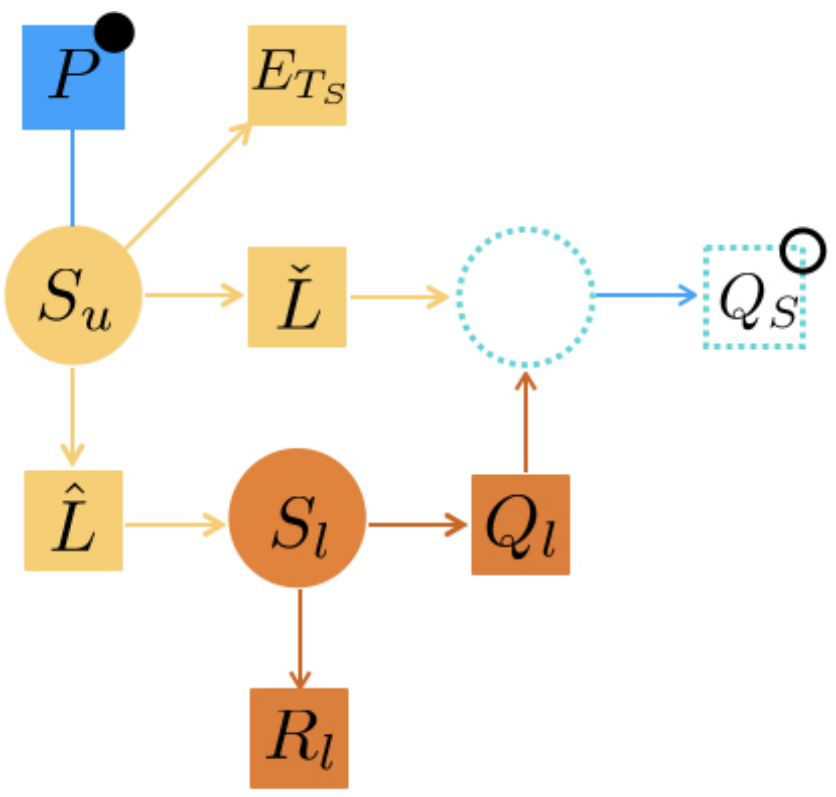

Shallow subsurface/Quick flow

Groundwater/Slow reservoir

\section{Surface Waters}

Figure 10. EPN representation of the Maimai catchment according to our reconstruction. It has two main reservoirs, a soil reservoir, $S_{u}$, and a groundwater reservoir, $S_{l}$. There is also a surface water reservoir, $S_{\text {sup }}$, where soil waters and groundwater mix without any delay (so it is an invisible place). In Gabrielli et al. (2018) soil water fluxes and groundwater fluxes were measured separately and, therefore, we mark them with a black bullet.

\section{Modeling Hydrology as an Earth System Science}

The HDSys are open dynamical systems that exchange water and energy with their surroundings. They are non-linear and usually non-autonomous, they have non-trivial time-dependent properties and, being open systems, their future inputs are unknown. Therefore, they differ from the dynamical systems treated in other disciplines where, for instance, forcings can be written as periodic functions (a typical example in textbooks is Strogatz (1994)).

One of the contemporary directions of hydrological research is to investigate HDSys as part of the larger Earth system science, which includes, among others, the energy and carbon cycles. Thus, the hydrological cycle becomes part of a broader living environment that feeds back on itself (H. H. G. Savenije \& Hrachowitz, 2017; Zehe et al., 2014). Ecosystems are not passive spectators of hydrological events but co-evolve with hydrology (H. G. Savenije \& Hrachowitz, 2017). According to this concept, ecosystems control the hydrological cycle (and vice versa, of course). To be able to represent such complexities, we have to ensure that EPN can represent the energy budget and vegetation growth just as well as it represents the water budget. For these aspects, clearly, the usual representation of a model as a complex of reservoirs falls short. 


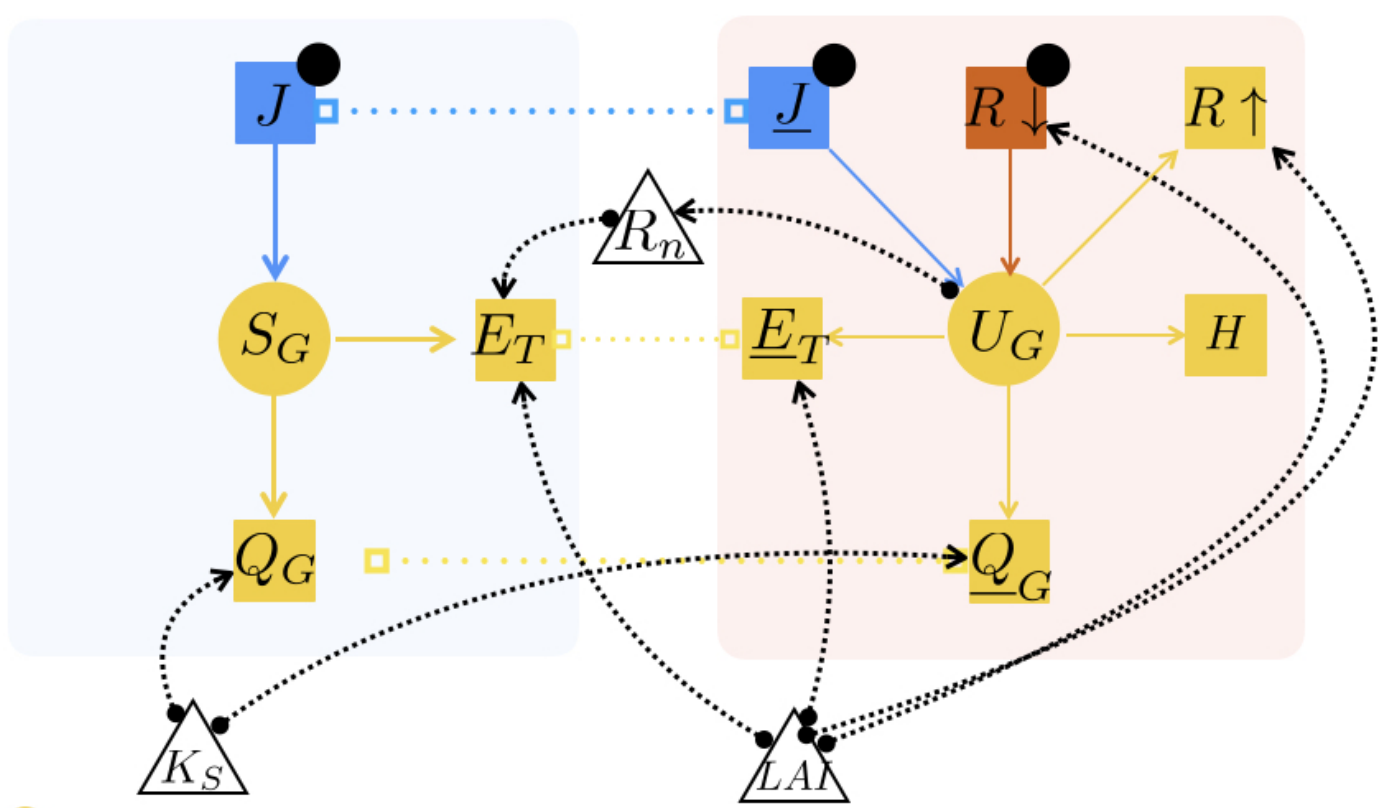

Hillslope Control Volume

Figure 11. Coupled energy and water budgets. The graphic notation is enriched with the addition of a new type of arc (dotted segments ending in empty squares). These arcs connect the same variables present in both budgets. In this case, the $J$ 's are input, while the $E_{T}$ 's and $Q_{G}$ 's are unknown variables that must be solved simultaneously in both budgets. Because $E_{T}$ depends on radiation, a controller exiting from the $U_{G}$ place is added to reveal this further influence of the energy budget on the water budget. Other controllers of the system can be the leaf area index, LAI, which controls radiation and evapotranspiration, and hydraulic conductivity, $K_{S}$, which can be thought to influence flow $Q_{G}$.

Rarely has the energy budget been present in hydrological models so far. Current studies, covering the whole set of hydrological fluxes (e.g. Abera, Formetta, Brocca, and Rigon (2017); Kuppel, Tetzlaff, Maneta, and Soulsby (2018)), require that both the water and energy budgets be solved. To describe this coupling we use the simple example shown in Figure 11(left), referring to a hillslope water budget, with the the associated energy budget also shown in Figure 11(right). To distinguish between the budgets, we used a further graphical stratagem in the figure and colored the background light pastel blue for the water budget and light pastel red for the energy budget).

The dictionary associated to the graph in Figure 11 (left) is in Table 4 and the budget can be deduced to be:

$$
\frac{d S_{g}(t)}{d t}=J(t)-E_{T}-Q_{g}
$$

The Expression Table is not needed at present and has been omitted.

In Figure 11(right), one can observe that the internal energy of the control volume contains one energy flux for each water flux present in the water budget. In fact, each mass flux has an associated internal energy, conveniently represented as enthalpy per unit mass, which flows in or out when mass is acquired or lost by the control volume. Thus, for instance, given the rainfall $J$, the corresponding enthalpy flux is $\underline{J}=\rho_{w} h_{w} J$, where $\rho_{w}$ is the water density in the volume, and $h_{w}$ is the water enthalpy per unit mass. In 
Table 4. Dictionary d relative to Figure 11. The underscoring (.) represents the internal energy acquired or lost through mass exchanges.

\begin{tabular}{llll}
\hline Symbol & Name & Type & Unit \\
\hline$[\mathrm{E}]$ & energy per unit area & - & {$[\mathrm{E}]$} \\
$E_{T}(t)$ & evapotranspiration & $\mathrm{F}$ & {$\left[L T^{-1}\right]$} \\
$E_{T}(t)$ & evapotranspiration energy content & $\mathrm{F}$ & {$\left[E L^{-2}\right]$} \\
$H$ & sensible heat & $\mathrm{F}$ & {$\left[E T^{-1}\right]$} \\
$J^{\bullet}(t)$ & precipitation rate & $\mathrm{F}$ & {$\left[L T^{-1}\right]$} \\
$J^{\bullet}(t)$ & precipitation energy content & $\mathrm{F}$ & {$\left[E T^{-1}\right]$} \\
$Q_{g}(t)$ & discharge & $\mathrm{F}$ & {$\left[L^{3} T^{-1}\right]$} \\
$Q_{g}(t)$ & discharge internal energy & $\mathrm{F}$ & {$\left[E T^{-1}\right]$} \\
$R^{\bullet} \downarrow$ & incoming radiation & $\mathrm{F}$ & {$\left[E T^{-1}\right]$} \\
$R \uparrow$ & outgoing radiation & $\mathrm{F}$ & {$\left[E T^{-1}\right]$} \\
$S_{g}(t)$ & water storage & $\mathrm{SV}$ & {$\left[L^{3}\right]$} \\
$t$ & time & $\mathrm{V}$ & {$[\mathrm{T}]$} \\
$U_{g}$ & internal energy & $\mathrm{SV}$ & {$[\mathrm{E}]$} \\
\hline & & &
\end{tabular}

short, many variables are common to both budgets, i.e. they are shared by the budgets and must satisfy both of them. These variables are joined by a new type of arc, a dotted segment capped with empty squares. In addition to these variables, in the energy budget we have to account for the radiation budget, written here as the budget of incoming $R \downarrow$ and outgoing, $R \uparrow$ radiation associated to the place $U_{G}$. Latent heat is accounted for as evapotranspiration multiplied by the latent heat (enthalpy) of vaporization. Finally, the energy flux due to thermal energy exchange by convection (sensible heat), flux $H$, is taken into account. The resulting energy budget equation is:

$$
\frac{d U_{G}}{d t}=\underline{J}+R \downarrow-R \uparrow-\underline{E}_{T}-H-\underline{Q}_{G}
$$

Table 5. Expression table E relative to the energy exchange model presented in Figure 11 on the right.

\begin{tabular}{lll}
\hline Symbol & Name & Unit \\
\hline$E_{T}(t)$ & evapotranspiration & {$\left[E T^{-1} L^{-2}\right]$} \\
\hline$H(t)$ & thermal convective flux & {$\left[E L^{-2} T^{-1}\right]$} \\
$J(t)$ & precipitation rate & {$\left[E T^{-1} L^{-2}\right]$} \\
$\mathcal{J}_{g}$ & thermal conduction losses to the ground & {$\left[E T^{-1} L^{-2}\right]$} \\
$Q_{g}(t)$ & discharge & {$\left[E T^{-1} L^{-2}\right]$} \\
$\frac{R_{n}(t)}{U_{g}(t)}$ & Net Radiation & {$\left[E L^{-2} T^{-1}\right]$} \\
\hline
\end{tabular}

Furthermore, hydraulic conductivity, $K_{S}$, is thought to control the water flux, $Q_{G}$, while the Leaf Area Index (LAI) controls evapotranspiration and radiation response of the system (through long wave radiation fluxes). Admittedly, some simplification have been made when coupling the water budget with the energy budget, however, the procedure is quite general and can be used for more complicated cases. 


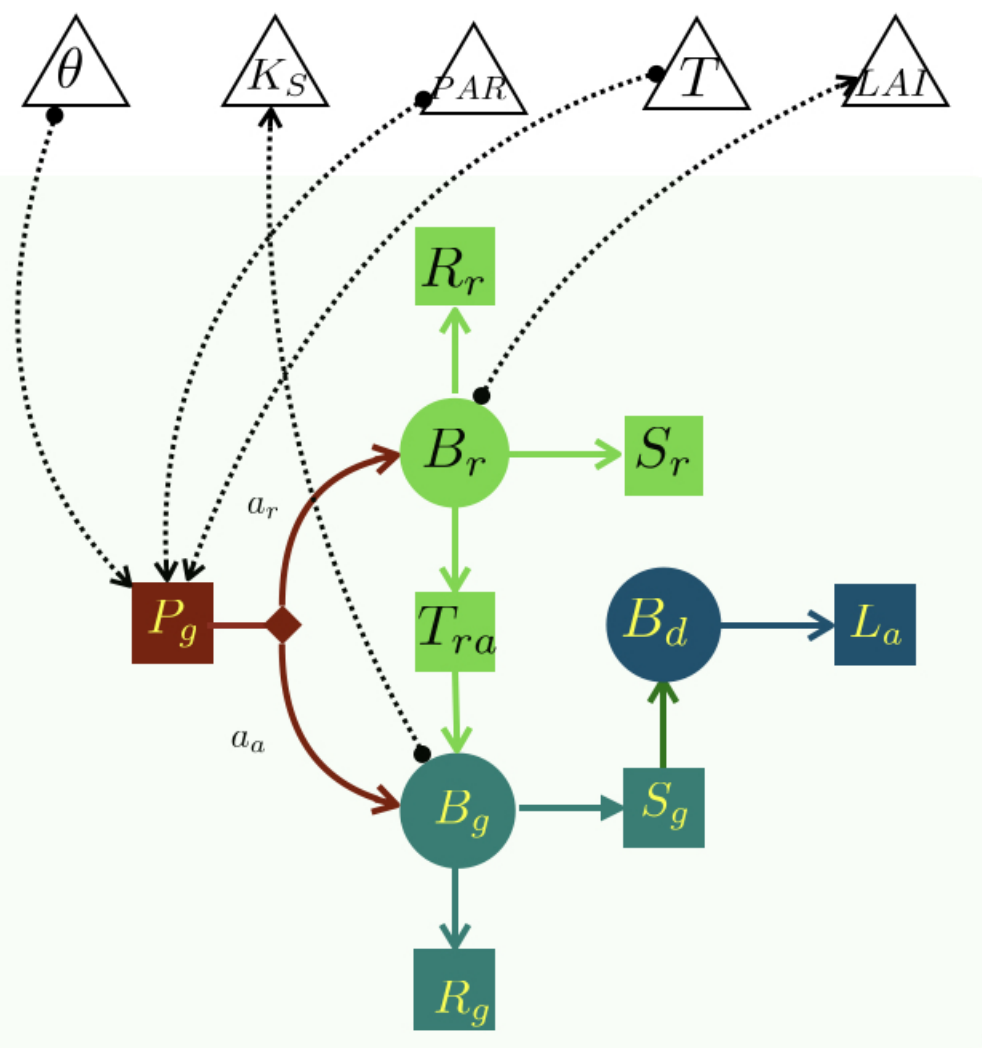

Below ground vegetation/Roots

Dead vegetation

Above ground vegetation

\subsection{Carbon budget}

The interactions of water budget with the ecosystem can also be represented with EPN. As an example, we use a simple vegetation growth model presented in Montaldo et al. (2005) and further developed in Della Chiesa et al. (2014). The model consists of three ODEs, for above ground vegetation, $B_{g}$, roots, $B_{r}$, and dead material, $B_{d}$ :

$$
\frac{d B_{g}}{d t}=a_{a} P_{g}+T_{r a}-R_{g}-S_{g}
$$

where $B_{g}$ is the mass of the green aboveground biomass, $P_{g}$ is the gross photosynthesis, $a_{a}$ is the allocation partition coefficient to shoots, $T_{r a}$ is the translocation of carbohydrates from the roots to the living aboveground biomass, $R_{g}$ is the respiration of the aboveground biomass, and $S_{g}$ the senescence of the aboveground biomass.

$$
\frac{d B_{r}}{d t}=a_{r} P_{g}-T_{r a}-R_{r}-S_{r}
$$

where $B_{r}$ is the living root biomass, $a_{r}\left(a_{r}+a_{a}=1\right)$ is the allocation partition coefficient to roots, $R_{r}$ is the respiration from roots, $S_{r}$ the senescence of roots.

$$
\frac{d B_{d}}{d t}=S_{g}-L_{a}
$$


where $B_{d}$ are the standing dead, $S_{g}$ is the senescence of aboveground biomass and $L_{A}$ is the litter fall. All of these quantities are described in the dictionary in Table 6 and are represented by the EPN in Figure 12. This model is presented to show how vegeta-

Table 6. Dictionary relative to the model of vegetation growth in Montaldo et al. (2005) and illustrated in Figure 12

\begin{tabular}{llll}
\hline Symbol & Name & Type & Unit \\
\hline$a_{a}$ & allocation partition coefficient for aboveground biomass & $\mathrm{P}$ & {$[-]$} \\
$a_{r}$ & allocation partition coefficient for root compartments & $\mathrm{P}$ & {$[-]$} \\
$B_{d}$ & standing dead biomass & $\mathrm{SV}$ & {$\left[\mathrm{M} \mathrm{L}^{-2}\right]$} \\
$B_{g}$ & green aboveground biomass & $\mathrm{SV}$ & {$\left[\mathrm{M} \mathrm{L}^{-2}\right]$} \\
$B_{r}$ & living root biomass & $\mathrm{SV}$ & {$\left[\mathrm{M} \mathrm{L}^{-2}\right]$} \\
$L_{a}$ & litter fall & $\mathrm{F}$ & {$\left[\mathrm{M} \mathrm{L}^{-2} \mathrm{~T}^{-1}\right]$} \\
$P_{g}$ & gross photosynthesis & $\mathrm{F}$ & {$\left[\mathrm{M} \mathrm{L}^{-2} \mathrm{~T}^{-1}\right]$} \\
$R_{g}$ & transpiration from aboveground biomass & $\mathrm{F}$ & {$\left[\mathrm{M} \mathrm{L}^{-2} \mathrm{~T}^{-1}\right]$} \\
$R_{r}$ & transpiration from root biomass & $\mathrm{F}$ & {$\left[\mathrm{M} \mathrm{L}^{-2} \mathrm{~T}^{-1}\right]$} \\
$S_{g}$ & senescence of the aboveground biomass & $\mathrm{F}$ & {$\left[\mathrm{M} \mathrm{L}^{-2} \mathrm{~T}^{-1}\right]$} \\
$S_{r}$ & senescence of the root biomass & $\mathrm{F}$ & {$\left[\mathrm{M} \mathrm{L}^{-2} \mathrm{~T}^{-1}\right]$} \\
$T_{r a}$ & translocation of carbohydrates from roots to the aboveground biomass & $\mathrm{F}$ & {$\left[\mathrm{M} \mathrm{L}^{-2} \mathrm{~T}^{-1}\right]$} \\
\hline
\end{tabular}

tion can interact with the hydrological cycle, an aspect that can be fully revealed only through an expression table. For the sake of simplicity, Table 7 does not contain the complete mathematical expressions, which are fully discussed in Della Chiesa et al. (2014); Montaldo et al. (2005), but it does provide the variable dependence needed to produce the h-connections between the vegetation model and the water and energy budgets. The

Table 7. Expression Table relative to the model of vegetation growth in Figure 13.

\begin{tabular}{lll}
\hline Symbol & Name & Expression \\
\hline$P_{g}$ & gross photosynthesis & $P_{g}\left(\Delta C O_{2}, r_{a}, r_{c}\right)$ \\
\hline
\end{tabular}

interesting fact is that, through parameters like the $L A I$, the aboveground vegetation controls evapotranspiration and radiation, while roots are thought to control the hydraulic conductivity, $K_{S}$. Photosynthesis feeds a vegetation system and is controlled by variables such as temperature, $T$, photosynthetic active radiation (here made dependent on the energy budget), and soil water content, $\theta$. All of this is represented in Figure 13 and is discussed in the next section.

\section{Discussion}

While the graphs of the water budget, energy budget and vegetation growth are themselves direct, acyclic graphs, the whole coupled graph, inclusive of h-wiring, shows loops, like the one between $U_{G} \rightarrow T \rightarrow P_{g} \rightarrow B_{r} \rightarrow L A I \rightarrow R \downarrow \rightarrow U_{G}$, that depict a feedback. Therefore, to really understand the interactions between the three dynamical systems graphically, we have to use h-wiring as we do in Figure 13. Notably, while the water budget can be represented with traditional reservoirs, the traditional graphics fall short in representing the other budgets. 


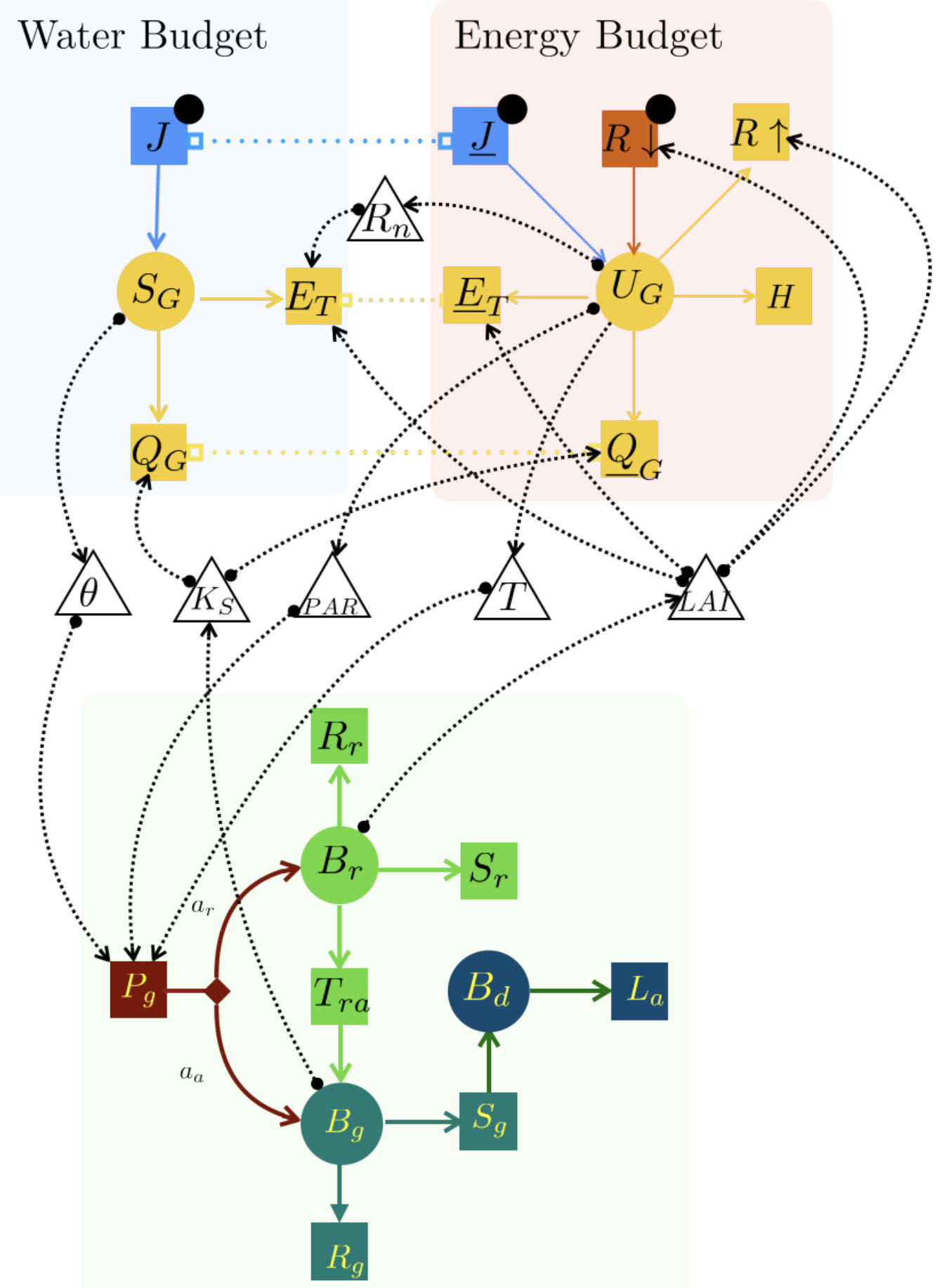

\section{Carbon Budget}

Figure 13. Representation of the water and energy budgets coupled with the vegetation dynamic model. The coupling happens entirely through h-wiring 
Figure 13 is only for demonstration purposes and, as such, the connections shown are hypothetical. As we have not implemented and tested such a model, the relations presented are based on educated guesses. The quantities that appear in the h-wiring network are constraints on the dynamical model parameters and work as valves that regulate the fluxes. Without h-wiring, the connections between sub-models are not evident. Although, the flux connections (f-wiring) alone are sufficient to write the correct ODEs in their completeness, including feedback loops, once complemented by the appropriate expression tables. When H. G. Savenije and Hrachowitz (2017) write, "The most important active agent in catchments is the ecosystem. [...]. Ecosystems do this in the most efficient way, establishing a continuous, ever-evolving feedback loop with the landscape and climatic drivers", they refer to the ability of ecosystems, represented in Figure 13 by the bottom set of ODEs, to control the water cycle. The Figure shows how this happens through the action of controllers that link vegetation to both the water and energy cycles. We do not know yet if the system devised includes the right properties to obtain the dynamical richness desired. To get an answer one should look towards system and control theories. These (Kalman, 1959) offer more than fifty years' worth of literature to help deal properly with interacting systems. In fact, one pivotal concept in system and control theories is controllability, i.e. the possibility that a system that has drifted into an undesirable state can be steered back to another desirable one. Linear theory (Willems, 2007) contains theorems and tools (Luenberger, 1979; Kalilath, 1980; Sontag, 1998) that can assess controllability precisely but, unfortunately, our HDSys is not linear and, at first sight, our controllers do not seem to fit the concept of actuators, the agents that perform the control.

To treat non-linearities more completely, more sophisticated analyses are needed, (Liu \& Barabasi, 2016). Fortunately, a lot has been accomplished since the 1970s (Haynes \& Hermes, 1970; Hermann \& Krener, 1977; Cornelius \& Kath, 2013). Great strides have been made, both from an analytical point of view and from a graph theory point of view, (Yamada \& Foulds, 1990; Liu \& Barabasi, 2016). Notably, the latter results are directly interpretable by using the EPN presented here, though an exploitation of these possibilities goes beyond the scopes of this paper. However, it should be noted that any graphical representation that does not contain fluxes in explicit form (i.e. as nodes of the graphs) and h-wiring, brings to a scanty graphical representations of the dynamics and, as a consequence, to incorrect graphical analyses.

The discussion so far has been referred to a single spatial unit or HRU. If a catchment is divided into various parts, the EPN of the single spatial units can be joined to obtain the integral distributed view of the basin. For illustrative purposes, in this paper we use a simple catchment partition based on the identification of subcatchments, as shown in Figure 14.

In the example case, the basin is subdivided in 5 HRUs (Figure 14, top left), which have been derived by dividing the river network into five links $C_{1}$ to $C_{5}$. It is assumed that the external fluxes to the HRU are rainfall $J_{i}$ in input, and evapotranspiration $E_{T i}$ and discharges $Q_{i}(i \in\{1, \ldots, 5\})$ in output. Each HRU flows into a channel stream, for instance, the HRU of area $A_{4}$ flows into $C_{4}$ and subsequently to $C_{5}$. The complete network of interactions can be represented as in Figure 14. A black frame marking some of the external places indicates that they are actually compound places. These can be expanded by using embedded models, like those shown in the Figures of the previous sections or some generalization of the more complex model of Figure 13. The HBV model (Seibert \& Vis, 2012) is meant to be just such a model: the HBV structure presented in Figures 2 and 8 can be used for any sub-catchment of the basin analyzed.

Figure 14 exploits the compositionality of EPN and shows how it can be used to represent any river network. Semi-distributed modeling can become very complex and even have heterogeneous elements in each compound node. It is not a matter for this paper to discuss when it becomes too complicated to be reasonably useful. The scopes of 


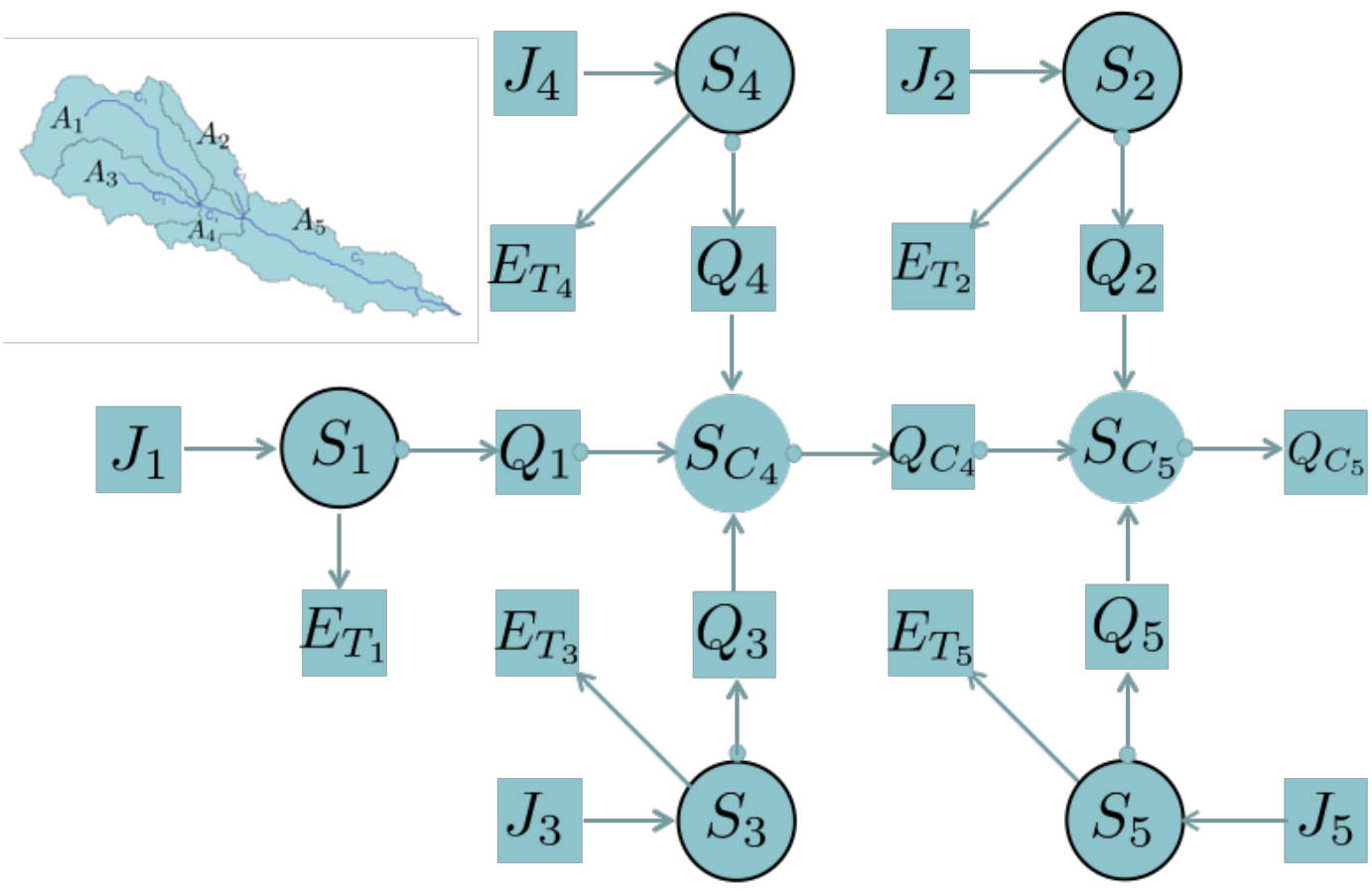

Figure 14. A small river networks with 5 HRUs (top left) and the corresponding EPN. There is a black frame marking some of the places to indicate that they are compound places; these should be expanded to reveal the full structure of the system.

our representation is to make the model structures presented as clear as possible and, eventually, to exemplify it. To pursue the latter task, it is helpful to translate the graphs into mathematics, as we do in the next section.

\section{A formal mathematical treatment of EPN}

So far we have treated the graphics and their relation to mathematics in a conversational way. However, these relations can be more precisely stated by providing a set of definitions for the entities appearing in EPN, which the reader can find below. The definitions have the advantage of formalizing the topology of the models by introducing appropriate adjacency and incidence matrixes. These matrixes, in turn, reveal that the structure of the hydrological dynamical system can be studied objectively using techniques derived by algebraic topology (Fiedler, 1973) and, as mentioned in the previous sections, already used in other fields Our definitions (any item marked with a bullet, •) expand the notation introduced in Navarro-Gutiérrez, Ramírez-Treviño, and Gómez-Gutiérrez (2013) and are modified as suggested by Baez and Pollard (2017). To exemplify them, we will refer to that part of the HBV model that has been framed in black in Figure 8.

\subsection{The topology of a HDSys}

- $\mathcal{P}=\left\{p_{1}, \cdot, p_{n}\right\}$ is the set of $n$ places (reservoirs). In our graphical notation, they are identified by $n$ circles. In the HBV example, $\mathcal{P}=\left\{S W E, W_{S}, S_{\text {soil }}\right\}$.

- $\mathcal{T}=\left\{t_{1}, \cdot, t_{l}\right\}$ is the set of $l$ transitions (fluxes). Graphically, they are represented by $l$ squares. In the HBV example, $\mathcal{T}=\left\{M, R, M_{d}, F, E_{\text {act }}, P\right\}$ 
In EPN the relationships between these two types of nodes (i.e. places and transitions) can be expressed with two incidence matrices.

- $A^{-}$is the incidence matrix that represents the connections from places to transitions, i.e. it is an $n \times l$ matrix, where the element $(i, j)$ is marked with 1 if place $i$ outputs to transition $j$ and otherwise it is 0 . In our graphical notation the connections are shown with oriented arcs joining the appropriate couple $\left(p_{i}, t_{j}\right)$. With respect to the $\mathrm{HBV}$ example, $A^{-}$is shown in table 8 .

\begin{tabular}{l|cccccc} 
& $R$ & $M$ & $M_{d}$ & $F$ & $E_{a c t}$ & $P$ \\
\hline SWE & 0 & 1 & 0 & 0 & 0 & 0 \\
$W_{s}$ & 1 & 0 & 1 & 0 & 0 & 0 \\
$S_{\text {soil }}$ & 0 & 0 & 0 & 1 & 1 & 0
\end{tabular}

Table 8. $A^{-}$matrix for the HBV example. $P$ is an input and has no places connecting to it, therefore, its column does not contain any $1 \mathrm{~s}$.

- $A^{+}$is the incidence matrix that represents connections from transitions to places, i.e. it is an $l \times n$ matrix, where the element $(k, m)$ is marked with 1 if transition $k$ is an input to place $m$; otherwise it is 0 . Graphically the connections are oriented arcs joining $\left(t_{k}, p_{m}\right)$ for the appropriate $k$ and $m$. The $A^{+}$matrix relative to the HBV example is shown in Table 9

\begin{tabular}{l|lll} 
& SWE & $W_{S}$ & $S_{\text {Soil }}$ \\
\hline$R$ & 1 & 0 & 0 \\
$M$ & 0 & 1 & 0 \\
$M_{d}$ & 0 & 0 & 1 \\
$F$ & 0 & 0 & 0 \\
$E_{\text {act }}$ & 0 & 0 & 0 \\
$P$ & 1 & 0 & 1
\end{tabular}

Table 9. The $A^{+}$matrix relative to the HBV model. $F$ and $E_{a c t}$ are outputs of the whole system and therefore their rows contain only 0 s.

There are two possible products of the incidence matrices, $A^{+}$and $A^{-}$, both of which result in a square matrix:

- $A=A^{-} \cdot A^{+}$is the $(n \times n)$ adjacency matrix that identifies the connections between places. The $A$ matrix for the HBV model is shown below in Table 10

\begin{tabular}{l|lll} 
& $S W E$ & $W_{S}$ & $S_{\text {Soil }}$ \\
\hline$S W E$ & 0 & 1 & 0 \\
$W_{S}$ & 1 & 0 & 1 \\
$S_{\text {Soil }}$ & 0 & 0 & 0
\end{tabular}

Table 10. The $A$ matrix for the HBV example. The anti-diagonal 1s reveal the presence of a loop. 
- $\tilde{A}=A^{+} \cdot A^{-}$is the $(l \times l)$ adjacency matrix that identifies the connection between transitions. The $\tilde{A}$ for the HBV example is presented in Table 11

\begin{tabular}{l|llllll} 
& $R$ & $M$ & $M_{d}$ & $F$ & $E_{a c t}$ & $P$ \\
\hline$R$ & 0 & 1 & 0 & 0 & 0 & 0 \\
$M$ & 1 & 0 & 1 & 0 & 0 & 0 \\
$M_{d}$ & 0 & 0 & 0 & 1 & 1 & 0 \\
$F$ & 0 & 0 & 0 & 0 & 0 & 0 \\
$E_{a c t}$ & 0 & 0 & 0 & 0 & 0 & 0 \\
$P$ & 0 & 1 & 0 & 1 & 1 & 0
\end{tabular}

Table 11. The $\tilde{A}$ adjacency matrix for transitions with respect to the HBV example. It reveals the connections between fluxes

Transitions and places, and their relationships as expressed in incidence and adjacency matrices, can be used to represent the ODE system of any budget (mass, energy, momentum).

Starting from any one of the places (circles), transitions (squares) in the graphic and:

- following the arcs we get a causal path. When two variables are connected by an arc, the upstream entity is said to cause the downstream one. Therefore a transition is caused by the upstream place and a place by the upstream fluxes. Causality is inherited, in that all upstream variables have causal influence on downstream ones.

However, the resulting EPN, do not show the feedbacks between state variables completely because some of these can be hidden in the flux expressions. Therefore, to provide a more complete visual representation of the causal relationships between variables, we have introduced the concept of controllers. Controllers are a function of a state variable (originated in a place) that contribute in the flux expressions of one or more transitions. They are explicitly represented by triangles in the graph. A rectangular incidence matrix $B$, of dimensions $(n \times l)$, indicates the places that are connected to transitions via controllers. The resulting web of interactions is called hidden wiring or $\mathbf{h}$-wiring. $B$ can be split into two matrices (as was the case for $A$ ).

If:

- $\mathcal{C}=\left\{c_{1}, \cdot, c_{m}\right\}$ is the set of controllers. In the HBV example there is just one controller, $T$, the temperature, therefore $\mathcal{C}=\{T\}$.

- $B^{-}$is the incidence matrix representing the connections from places to controllers. It is an $n \times m$ matrix with the non-null element $(i, j)$ set to 1 if place $i$ is connected to controller $j$. Graphically, oriented dashed arcs are used to connect circles to triangles. The $B^{-}$matrix of the HBV example is represented in Table 12.

- $B^{+}$is the incidence matrix $(m \times l)$ between controllers and transitions. Graphically the connection between controllers and transitions are represented by oriented dashed arcs between triangles and squares. The usual example from the HBV model reads as in Table 13 .

Then: 


\begin{tabular}{l|l} 
& $T$ \\
\hline$S W E$ & 0 \\
$W_{s}$ & 0 \\
$S_{\text {Soil }}$ & 1
\end{tabular}

Table 12. Matrix of the connections between places and controllers in the HBV example.

\begin{tabular}{l|llllll} 
& $R$ & $M$ & $M_{d}$ & $F$ & $E_{a c t}$ & $P$ \\
\hline$T$ & 1 & 1 & 0 & 0 & 1 & 1
\end{tabular}

Table 13. $B^{+}$matrix relative to the HBV example.

- the incidence matrix describing h-wiring is $B=B^{-} \cdot B^{+} ; B$ for the HBV example is shown in Table 14.

\begin{tabular}{l|cccccc} 
& $R$ & $M$ & $M_{d}$ & $F$ & $E_{a c t}$ & $P$ \\
\hline$S W E$ & 0 & 0 & 0 & 0 & 0 & 0 \\
$W_{s}$ & 0 & 0 & 0 & 0 & 0 & 0 \\
$S_{\text {Soil }}$ & 1 & 1 & 0 & 0 & 1 & 1
\end{tabular}

Table 14. Incidence matrix between the places and transition generated by h-wiring in the HBV example.

- the adjacency matrix $C=B^{-} \cdot B^{+} \cdot A^{+}$describes the h-connections between places (via flux controllers). This adjacency matrix is shown in Table 15 with respect to the HBV example. Unlike the other adjacency and incidence matrixes, there are 2 connections between $S_{\text {soil }}$ and $S W E$, due to the multiple arrows exiting from $T$. Also interesting is the self-loop for $S_{\text {Soil }}$ through precipitation separation, since temperature is thought to be affected by soil water quantity. We note here that this feedback is not contained in the HBV model; it is introduced here only for illustrative purposes.

\begin{tabular}{|c|c|c|c|}
\hline & $S W E$ & $W_{s}$ & $S_{\text {Soil }}$ \\
\hline$S W E$ & 0 & 0 & 0 \\
\hline$W_{s}$ & 0 & 0 & 0 \\
\hline$S_{\text {Soil }}$ & 2 & ${ }^{1}$ & $\begin{array}{c}1 \\
\text { ble } 15 .\end{array}$ \\
\hline
\end{tabular}

- The total adjacency matrix $D:=A+C$ contains all the connections between places, both with and without controllers. $D$ for the HBV example is shown in Table 16. The h-wiring introduces feedback between $S_{\text {soil }}$ and $W_{s}$, which was not apparent without it.

Therefore, to define EPN and its information, we need a 7-tuple:

- $\mathcal{X}=\left(\mathcal{P}, \mathcal{T}, \mathcal{C}, A^{-}, A^{+}, B^{-}, B^{+}\right)$, respectively representing: places, transitions, controllers, incidence matrix from places to transitions, from trasitions to places, from 


\begin{tabular}{l|lll} 
& SWE & $W_{s}$ & $S_{\text {Soil }}$ \\
\hline$S W E$ & 0 & 1 & 0 \\
$W_{s}$ & 1 & 0 & 1 \\
$S_{\text {Soil }}$ & 2 & 1 & 1
\end{tabular}

Table 16. The $D$ matrix for the HBV example. It represents all the connections between places, either mediated by fluxes or by h-wiring.

places to controllers, and from controllers to transitions, that we call the topology of the EPN.

Models with the same topology can have different fluxes and state variables.

\subsection{The semantics of a HDSys}

The semantics provide all the information needed to complete the equations of a given system on the basis of its topology. Let us define the semantics as follows.

Let:

- D be the dictionary or lexicon of a model. It associates each symbol in the topology to its meaning (and other information such as units and the role of the variable). Various examples were given in the previous sections, such as Tables 1 above and Table A.1 below.

- $\dot{\mathrm{S}}$ be the set of expressions for places, associating to each place its mathematical operator (in this paper the default expression for a place is the time derivative of the state variable);

- E be the set of expressions for fluxes, associating to each flux its algebraic form. Examples are given in Tables 2 and B;

- $\mathrm{C}$ be the set of expressions that define controllers as functions of state variables. Table B3 is an example for the Ard-Burn example.

Then,

- the semantics of an EPN is the quadruple: $\mathcal{Y}=(\mathrm{D}, \mathrm{E}, \mathrm{C}, \dot{\mathrm{S}})$

Finally,

- The pair $\mathcal{M}=(\mathcal{X}, \mathcal{Y})$ (topology and semantics) fully defines a HDSys.

\subsection{A definition of hydrological dynamical systems}

Some further definitions can be useful in understanding the nature of the model $\mathcal{M}$.

The set:

- $s_{i}=\left\{p_{j} \mid A_{j i}^{-}>0\right\}$ is said to be the preset (or the set of sources) of the transition $t_{i}$; In Table 8 this set can be deduced from the non-null terms in the columns.

- $o_{i}=\left\{p_{j} \mid A_{i, j}^{+}>0\right\}$ is said to be the postset or the set of targets of transition $t_{i}$. In Table 9 they are the non-null terms in any row.

Then, 
- A system is said to be open if there are transitions with both empty presets (rows with all zeroes in Table 9) and empty postsets (columns with all zeroes in Table 8). Otherwise, a system is said to be closed. Please note that a topology with empty presets but non-empty postsets (or, vice versa, with empty postsets and non-empty presets) is dynamically meaningless.

Analogously, the same definitions of preset and postset can be used for controllers:

- $u_{i}=\left\{p_{j} \mid B_{i j}^{-}>0\right\}$ is said to be the preset of the controller $c_{i}$,

- $v_{i}=\left\{p_{j} \mid B_{i j}^{+}>0\right\}$ is said to be the postset of the controller $c_{i}$

Therefore, we can conclude that:

- any open or closed system, as defined above, can be externally constrained if there are controllers with empty presets.

Observing that the set of expressions of fluxes, E, is a column (tuple) of symbols of length $l$, like the transitions to which it is associated, we can build the vectors of expressions:

- $O=A^{-} \cdot$ E, where the element $O_{j}$ contains all the output fluxes from place $j$; and

- $I=\tilde{A}^{+} \cdot \mathrm{E}$, where $\tilde{A}^{+}$is the transpose of the incidence matrix $A^{+}$and the element $I_{j}$ contains all the inputs to place $j$.

Applying these definitions, any HDSys can be written as:

$$
\dot{\mathrm{S}}=\left(\tilde{A}^{+}-A^{-}\right) \cdot \mathrm{E}=I-O
$$

where $\dot{\mathrm{S}}$ is the tuple of differential operators acting on place variables. This can be expressed in terms of the components:

$$
\frac{d S_{j}}{d t}=\left(\left(\tilde{A}^{+}-A^{-}\right) \cdot \mathrm{E}\right)_{j}=\tilde{A}_{j i}^{+} \mathrm{E}_{i}-A_{j i}^{-} \mathrm{E}_{i}=I_{j}-O_{j}
$$

where, the substitution $S_{j} \rightarrow \frac{d S_{j}}{d t}$ has been assumed for all the state variables in $\dot{\mathrm{S}}$ and the sum of all the transitions that connect to the place $j$ is implicit in the tuple product.

\subsection{Composition of models and feedbacks}

Models are compositional in the sense that, given two model $\mathcal{M}$ and $\mathcal{M}^{\prime}$, we say that

- $\mathcal{M}$ and $\mathcal{M}^{\prime}$ can be composed if at least one output of one model coincides with one input of the other.

However, models can also be composed by sharing controllers. For instance, a model of the energy budget can provide the temperature $T$, which is a controller of the model HBV. Thence, the energy budget not only constrains the behavior of $H B V$ but can also be composed with it. We can say that, given two models $\mathcal{M}$ and $\mathcal{M}^{\prime}$, they can be composed:

- by sharing fluxes (f-wiring); or

- by sharing controllers (h-wiring )

This means that our models, and their representations, have at least two associative properties that can be used to obtain arbitrarily complicated models. The use of h-wiring is 
only fully possible with a Petri net type of representation because in other graphical systems, fluxes (transitions) do not have the graphical status of nodes.

\section{Conclusions}

In this paper we introduced an extension of Petri Nets to describe lumped hydrological models and make evident that they are part of the great family of dynamical systems and/or compartmental models. The EPN representation:

- is adequate to describe any lumped hydrological system and the interactions between the hydrological, energy and carbon cycles, which form the basis for the modelling of Earth system interactions.

- standardizes the way to represent hydrological models and interactions;

- streamlines the process of documenting hydrological models;

- facilitates user comprehension of eco-hydrological interactions (number of places corresponds to the number of equations, number of transitions to the number of fluxes, and number of controllers to the number of constraints imposed on the fluxes);

- can be used to organize process interactions hierarchically, even when the mathematical flux expressions are not set;

- allows for an easy comparison of model structures in terms of topology and semantics (via specific expression of fluxes and constraints);

- visually represents feedback loops between subcomponents, even those implied by non-linear terms, that are hidden in other treatments of the subject;

- provides a complete visual representation of the causal relation between variables used in models;

- helps to understand lumped models as systems of systems of ODEs that can be composed to form larger systems;

- builds a bridge with analysis techniques developed in mathematics or other disciplines, such as theoretical biology, neuroscience and computer science;

- hints how results from linear and non-linear Systems and Control theory can be used to gain insight into hydrological processes and evaluate the control exerted by ecosystems on hydrology and by hydrology on ecosystems.

At the same time, being general, EPN can be easily used in other disciplines, such as ecology, chemistry, biology and population dynamics. 


\section{A Dictionaries and Expression table for the HBV model}

In this Appendix we report the Dictionary and the Expression table for the HBV model. The information presented, together with the EPN, allows one to write the dynamical system that corresponds to the HBV model with confidence.

Table A.1. Dictionary for the HBV model Seibert and Vis (2012). P type stands for "parameter"; $F$ for "flux"; $S V$ for "state variable"; $C$ for controller; $V$ for independent variable

\begin{tabular}{|c|c|c|c|}
\hline Symbol & Name & Type & Units \\
\hline$E_{a c t}$ & actual evapotranspiration & $\mathrm{F}$ & {$\left[\mathrm{L} \mathrm{T}^{-1}\right]$} \\
\hline$E_{\text {pot }}$ & potential evapotranspiration & $\mathrm{F}$ & {$\left[\mathrm{L} \mathrm{T}^{-1}\right]$} \\
\hline$E_{P O T, M}$ & long term mean potential evapotranspiration & $\mathrm{P}$ & {$\left[\mathrm{L} \mathrm{T}^{-1}\right]$} \\
\hline$F(t)$ & flux of water to the upper reservoir & $\mathrm{F}$ & {$\left[\mathrm{L} \mathrm{T}^{-1}\right]$} \\
\hline$M$ & rate of snow melting & $\mathrm{F}$ & {$\left[\mathrm{L} \mathrm{T}^{-1}\right]$} \\
\hline$M_{d}$ & release of liquid water from snow & $\mathrm{F}$ & {$\left[\mathrm{L} \mathrm{T}^{-1}\right]$} \\
\hline$P^{\bullet}$ & precipitation & $\mathrm{F}$ & {$\left[\mathrm{L} \mathrm{T}^{-1}\right]$} \\
\hline$P_{B E T A}$ & exponent in flux to upper zone & $\mathrm{P}$ & {$[-]$} \\
\hline$P_{C F M A X}$ & degree-day factor in snow melting & $\mathrm{P}$ & {$\left[\mathrm{L} \mathrm{T}^{-1}\right]$} \\
\hline$P_{C F R}$ & proportion of water refreezing & $\mathrm{P}$ & {$[-]$} \\
\hline$P_{C E T}$ & parameter in defining $E_{P O T}$ & $\mathrm{P}$ & {$[\mathrm{T}-1]$} \\
\hline$P_{F C}$ & maximum value of soil storage & $\mathrm{P}$ & {$[\mathrm{L}]$} \\
\hline$P_{K 0}$ & parameter in estimation of flux out of upper zone & $\mathrm{P}$ & {$\left[\mathrm{T}^{-1}\right]$} \\
\hline$P_{K 1}$ & parameter in estimation of flux out of upper zone & $\mathrm{P}$ & {$\left[\mathrm{T}^{-1}\right]$} \\
\hline$P_{K 2}$ & parameter in estimation of flux out of LZ & $\mathrm{P}$ & {$\left[\mathrm{T}^{-1}\right]$} \\
\hline$P_{L T}$ & parameter: entering in evaporation estimation & $\mathrm{P}$ & {$[-]$} \\
\hline$P_{\text {perc }}$ & percolation to groundwater & $\mathrm{F}$ & {$\left[\mathrm{L} \mathrm{T}^{-1}\right]$} \\
\hline$P_{M A X B A S}$ & parameter: in definition of $c(i)$ & $\mathrm{P}$ & {$[-]$} \\
\hline$P_{T T}$ & threshold parameter for melting activation & $\mathrm{P}$ & {$[\mathrm{T}]$} \\
\hline$Q_{G W 1}$ & runoff from the upper zone to the surface waters & $\mathrm{F}$ & {$\left[\mathrm{L} \mathrm{T}^{-1}\right]$} \\
\hline$Q_{G W 2}$ & groundwater flow & $\mathrm{F}$ & {$\left[\mathrm{L} \mathrm{T}^{-1}\right]$} \\
\hline$Q_{\text {sim }}$ & river network discharge & $\mathrm{F}$ & {$\left[\mathrm{L} \mathrm{T}^{-1}\right]$} \\
\hline$R$ & rate of liquid water refreezing & $\mathrm{F}$ & {$\left[\mathrm{L} \mathrm{T}^{-1}\right]$} \\
\hline$S_{\text {soil }}$ & water in soil/root zone & SV & {$[\mathrm{L}]$} \\
\hline$S_{L Z}$ & groundwater storage & SV & {$[\mathrm{L}]$} \\
\hline$S_{R}$ & runoff storage & SV & {$[\mathrm{L}]$} \\
\hline$S_{U Z}$ & water Storage in the upper zone & SV & {$[\mathrm{L}]$} \\
\hline$S W E$ & Snow Water Equivalent & SV & {$[\mathrm{L}]$} \\
\hline$T^{\bullet}$ & temperature & $\mathrm{C}$ & {$[\mathrm{T}]$} \\
\hline$T_{M}$ & long-term average temperature & $\mathrm{P}$ & {$[\mathrm{T}]$} \\
\hline$W_{S}$ & liquid water in snow & SV & {$[\mathrm{L}]$} \\
\hline
\end{tabular}

The expressions in Table A.2 are quite long, given our desire to respect the names used in the paper Seibert and Vis (2012); we are forced, therefore, to introduce the ancillary table A.3 that contains the missing sub-expressions. Once sub-expressions are substituted into their corresponding variable, the complete form of the fluxes is obtained.

\section{B Dictionary and Expression table for the Loch Ard-Burn model}

Here we present the dictionary and the expression table for the Loch Ard-Burn model. Notwithstanding the apparent simplicity of Figure 3, the model becomes quite complicated when complete information is provided. 
Table A.2. Expression table for HBV model. The flux expressions are quite long and, therefore, some ancillary quantities are defined in table A.3

\begin{tabular}{lll}
\hline Flux & Name & Expression \\
\hline$E_{a c t}$ & actual evapotranspiration & $E_{\text {pot }} \min \left(\frac{S_{\text {soil }}(t)}{P_{F C} P_{L T}}, 1\right)$ \\
$F(t)$ & flux of water to the upper reservoir & $I(t)\left(\frac{S_{\text {soil }}}{P_{F C}}\right)$ \\
$\mathrm{M}$ & rate of snow melting & $P_{C F M A X}\left(T(t)-P_{T T}\right)$ \\
$M_{d}$ & release of liquid water from snow & $M-R$ \\
$P$ & precipitation & $\bullet$ \\
$P_{\text {perc }}$ & percolation to groundwater & \\
$Q_{G W 1}$ & runoff from the upper zone & $P_{K 2} S_{L Z}$ \\
$Q_{G W 2}$ & to the surface waters & \\
$Q_{s i m}$ & river network discharge & $P_{K 0} \max \left(S_{U Z}-P_{U Z L}, 0\right)+P_{K 1} S_{U Z}$ \\
$R$ & rate of liquid water refreezing & $\sum_{i=1}^{P_{M A} A S} c(i)\left(Q_{G W 1}(t-i+1)+\right.$ \\
\hline
\end{tabular}

Table A.3. Table of ancillary variables in the HBV model Expression Table

\begin{tabular}{lll}
\hline Variable & Name & Expression \\
\hline$c(i)$ & ancillary variable in $Q_{\text {sim }}$ & $\int_{i-1}^{i} \frac{2}{P_{M A X B A S}}-\left|u-\frac{P_{M A X B A S}}{2}\right| \frac{4}{P_{M A X B A S}^{2}} d u$ \\
$E_{p o t}$ & potential evapotranspiration & $\left.\left(1+P_{C E T}\left(T(t)-T_{M}\right)\right) E_{\text {pot }, M}\right)$ \\
$\mathrm{I}(\mathrm{t})$ & sum of snow melt and precipitation & $S_{\text {soil }}+M_{D}$ \\
\hline
\end{tabular}

Table B.1. Dictionary for the Loch Ard-Burn model. Most of the nomenclature derives from (Hrachowitz et al., 2013). However, in that paper, the $S_{O}$ reservoir is not drawn and, in our opinion, some symbols were not named properly; the underlined words represent more appropriate names, in our opinion.

\begin{tabular}{llll}
\hline Symbol & Name & Type & Units \\
\hline$C_{E}$ & partition coefficient between evapotranspirations & $\mathrm{C}$ & {$[-]$} \\
$C_{R}$ & partition coefficients between runoff types & $\mathrm{P}$ & {$[-]$} \\
$E_{p}$ & potential Evapotranspiration & $\mathrm{F}$ & {$\left[\mathrm{L} \mathrm{T}^{-1}\right]$} \\
$E_{S I}$ & evaporation from vegetation & $\mathrm{F}$ & {$\left[\mathrm{L} \mathrm{T}^{-1}\right]$} \\
$E_{S U}$ & transpiration from unsaturated reservoir & $\mathrm{F}$ & {$\left[\mathrm{L} \mathrm{T}^{-1}\right]$} \\
$E_{S F}$ & transpiration from fast responding reservoir & $\mathrm{F}$ & {$\left[\mathrm{L} \mathrm{T}^{-1}\right]$} \\
$h_{F}$ & response time distribution for $X_{F}$ reservoir & {[]} & {$\left[\mathrm{T}^{-1}\right]$} \\
$h_{S}$ & response time distribution for $X_{S}$ reservoir & {[]} & {$\left[\mathrm{T}^{-1}\right]$} \\
$K_{F}$ & storage coefficient of fast reservoir & $\mathrm{P}$ & {$\left[\mathrm{T}^{-1}\right]$} \\
$K_{S}$ & storage coefficient of slow reservoir & $\mathrm{P}$ & {$\left[\mathrm{T}^{-1}\right]$} \\
$I_{m a x}$ & maximum interception & $\mathrm{P}$ & {$[\mathrm{L}]$} \\
$L_{p}$ & transpiration threshold & $\mathrm{P}$ & {$[-]$} \\
$P_{\text {max }}$ & percolation capacity & $\mathrm{P}$ & {$\left[\mathrm{L} \mathrm{T}{ }^{-1}\right]$} \\
$P_{R}^{\circ}$ & rainfall & $\mathrm{F}$ & {$\left[\mathrm{L} \mathrm{T}^{-1}\right]$} \\
$P_{T F}$ & throughfall & $\mathrm{F}$ & {$\left[\mathrm{L} \mathrm{T}^{-1}\right]$} \\
$Q_{S F}$ & runoff from fast reservoir & $\mathrm{F}$ & {$\left[\mathrm{L} \mathrm{T}^{-1}\right]$} \\
$Q_{O F}$ & overland flow & $\mathrm{F}$ & {$\left[\mathrm{L} \mathrm{T}^{-1}\right]$} \\
$Q_{S S}$ & runoff from slow reservoir & $\mathrm{F}$ & {$\left[\mathrm{L} \mathrm{T}^{-1}\right]$} \\
$R_{F}$ & recharge of fast reservoir & $\mathrm{F}$ & {$\left[\mathrm{L} \mathrm{T}^{-1}\right]$} \\
$R_{O}$ & flux from hidden old water reservoir to unsaturated zone & $\mathrm{F}$ & {$\left[\mathrm{L} \mathrm{T}^{-1}\right]$} \\
\hline
\end{tabular}




\begin{tabular}{llll}
\hline Symbol & Name & Type & Units \\
\hline$R_{P}$ & preferential recharge of slow reservoir & $\mathrm{F}$ & {$\left[\mathrm{L} \mathrm{T}^{-1}\right]$} \\
$R_{S}$ & recharge of old water reservoir & $\mathrm{F}$ & {$[\mathrm{L}] \mathrm{T}^{-1}$} \\
$R_{U}$ & percolation from the unsaturated reservoir & $\mathrm{F}$ & {$\left[\mathrm{L} \mathrm{T}^{-1}\right]$} \\
$S_{I}$ & intercepted storage & $\mathrm{SV}$ & {$[\mathrm{L}]$} \\
$S_{O}$ & passive storage in old water reservoir & $\mathrm{SV}$ & {$[\mathrm{L}]$} \\
$S_{S}$ & storage in slow reservoir & $\mathrm{SV}$ & {$[\mathrm{L}]$} \\
$S_{U}$ & storage in unsaturated reservoir & $\mathrm{SV}$ & {$[\mathrm{L}]$} \\
$S_{U_{m a x}}$ & storage capacity in unsaturated reservoir & $\mathrm{P}$ & {$[\mathrm{L}]$} \\
$T_{F}$ & concentration time for fast reservoir & $\mathrm{P}$ & {$[\mathrm{T}]$} \\
$T_{S}$ & concentration time for slow reservoir & $\mathrm{P}$ & {$[\mathrm{T}]$} \\
$X_{F}$ & reservoir creating lag time between $S_{U} \rightarrow S_{F}$ & $\mathrm{SV}$ & {$[\mathrm{L}]$} \\
$X_{S}$ & reservoir creating lag time between $S_{U} \rightarrow S_{S}$ & $\mathrm{SV}$ & {$[\mathrm{L}]$} \\
$\beta$ & shape parameter & $\mathrm{P}$ & {$[-]$} \\
\hline
\end{tabular}

Table B.2. Expression table for the Loch Ard-Burn model. It contains expressions for all the fluxes. It requires an ancillary table for all the new definitions included in the expressions.

\begin{tabular}{lll}
\hline Variable & Name & Expression \\
\hline$E_{S I}$ & evaporation from vegetation & $\min \left(S_{I} / d t, E_{p}\right)$ \\
$E_{S U}$ & transpiration from unsaturated reservoir & $E_{p} C_{E} \min \left(1, S_{U} /\left(S_{U_{\max }} L_{p}\right)\right)$ \\
$E_{S F}$ & transpiration from fast responding reservoir & $\min \left(E_{p}\left(1-C_{E}\right), S_{F} / d t\right)$ \\
$P_{R}$ & Rainfall & $\bullet$ \\
$P_{T F}$ & throughfall & $P_{R}-\min \left(\left(I_{\max }-S_{I}\right) / d t\right)$ \\
$Q_{S F}$ & runoff from fast reservoir & $K_{F} S_{F}$ \\
$Q_{O F}$ & overland flow & $\max \left(S_{F}-S_{F_{\max }}, 0\right)$ \\
$Q_{S S}$ & runoff from slow reservoir & $K_{S} S_{S}$ \\
$R_{F}$ & recharge of fast reservoir & $C_{R}\left(1-C_{p}\right) P_{T F}$ \\
$R_{F}^{*}$ & delayed flux from fast reservoir & $R_{F} \star h_{F}$ \\
$R_{O}$ & flux from hidden old water reservoir to unsaturated zone & $\equiv R_{S}$ \\
$R_{P}$ & preferential recharge of slow reservoir & $C_{R} C_{P} C_{E}$ \\
$R_{S}$ & recharge of old water reservoir & $P_{\max }\left(S_{U} / S_{U_{\max }}\right)$ \\
$R_{S}^{*}$ & delayed flux from slow reservoir & $R_{S} \star h_{S}$ \\
$R_{U}$ & percolation from the unsaturated reservoir & $\left(1-C_{R}\right) P_{E}$ \\
\hline & &
\end{tabular}

Table B.3. Ancillary variables of the Loch Ard-Burn dictionary introduced by the flux expressions

\begin{tabular}{lll}
\hline Symbol & Name & Expression \\
\hline$C_{R}$ & coefficient of partition between runoff types & $\left(1+\exp \left(-S_{U} / S_{U_{\max }}+0.5\right)\right)^{-1}$ \\
$h_{F}$ & response time distribution for $X_{f}$ reservoir & $2\left(t / T_{F}^{2}\right)$, for $0<t<T_{F} ; 0$ elsewhere \\
$h_{S}$ & response time distribution for $X_{S}$ reservoir & $2\left(t / T_{S}^{2}\right)$, for $0<t<T_{S} ; 0$ elsewhere \\
\hline
\end{tabular}

Table B.4. Controllers table in the Ard Burn model

\begin{tabular}{lll}
\hline Symbol & Name & Expression \\
\hline$C_{E}$ & coefficient of partition between evapotranspirations & $S_{U} /\left(S_{U}+S_{F}\right)$ \\
$E_{p}$ & potential evapotranspiration & $?$ \\
\hline
\end{tabular}




\section{Acknowledgments}

This work was partially supported by the Steep Streams project. All the Authors participated equally all the phases of the research. We do not have used data in our paper. Finally the Authors thank the Associate Editor, Thorsten Wagener, and three anonymous reviewers for their comments that helped to greatly improve this paper.

\section{References}

Abera, W., Formetta, G., Brocca, L., \& Rigon, R. $\quad$ (2017). Modeling the water budget of the upper blue nile basin using the jgrass-newage model system and satellite data. Hydrology and Earth System Sciences, 21(6), 3145.

Alla, H., \& David, R. (1998). Continuous and hybrid petri nets. Journal of Circuits, Systems, and Computers, 8(01), 159-188.

Baez, J. C., \& Biamonte, J. (2012). Quantum techniques for stochastic mechanics. arXiv preprint arXiv:1209.3632.

Baez, J. C., \& Pollard, B. S. (2017). A compositional framework for reaction networks. Reviews in Mathematical Physics, 29(09), 1750028.

Berthomieu, B., \& Diaz, M. (1991). Modeling and verification of time dependent systems using time petri nets. IEEE transactions on software engineering, $17(3), 259-273$.

Beven, K. J. (2011). Rainfall-runoff modelling: the primer. John Wiley \& Sons.

Birkel, C., Soulsby, C., \& Tetzlaff, D. (2011). Modelling catchment-scale water storage dynamics: reconciling dynamic storage with tracer-inferred passive storage. Hydrological Processes, 25 (25), 3924-3936.

Butts, M. B., Payne, J. T., Kristensen, M., \& Madsen, H. (2004). An evaluation of the impact of model structure on hydrological modelling uncertainty for streamflow simulation. Journal of Hydrology, 298, 242-266. Retrieved from http://doi.org/10.1016/j.jhydrol.2004.03.042

Carrera, J., Holzbecher, E., Bonell, M., \& Vasiliev, O. F. ～(2005). Systems approach: the nature of coupled models. In A. Brontstert, B. Kabat, J. Carrera, \& S. Ltkemeier (Eds.), Coupled models of the hydrological cycle (p. 75-164). Springer.

Champagnat, R., Esteban, P., Pingaud, H., \& Valette, R. (1998). Modeling and simulation of a hybrid system through pr/tr pn-dae model. In Adpm (Vol. 98, pp. 131-137).

Clark, M. P., Nijssen, B., Lundquist, J. D., Kavetski, D., Rupp, D. E., Woods, R. A., ... Rasmussen, R. (2015). A unified approach for process-based hydrologic modeling: 1. modeling concept. Water Resources Research, 51 (4), 2498-2514. Retrieved from http://doi.org/10.1002/2015WR017198

Clark, M. P., Slater, A. G., Rupp, D. E., Woods, R. A., Vrugt, J. A., Gupta, H. V., ... Lauren, E. H. (2008). Framework for understanding structural errors (fuse): A modular framework to diagnose differences between hydrological models. Water Resources Research, 44, 1-14. Retrieved from http://doi .org/10.1029/2007WR006735

Cornelius, S. P., \& Kath, A. E., W. L.and Motter. (2013). Realistic control of network dynamics. Nature Communications, 4, 1942.

Della Chiesa, S., Bertoldi, G., Niedrist, G., Obojes, N., Endrizzi, S., Albertson, J., ... Tappeiner, U. (2014). Modelling changes in grassland hydrological cycling along an elevational gradient in the alps. ecohydrology. Ecohydrology, 7, 1453-1473. doi: 10.1002/eco.1471

Fenicia, F., \& Kavetski, H. H. G., D. anf Savenije. (2011). Elements of a flexible approach for conceptual hydrological modeling: 1. motivation and theoretical development. Water Resources Research, 47(11), W11510,1-13. Retrieved from http://doi .org/10.1029/2010WR010174 
Fenicia, F., Savenije, H. H., Matgen, P., \& Pfister, L. (2008). Understanding catchment behavior through stepwise model concept improvement. Water Resources Research, $44(1)$.

Fenicia, F., Wrede, S., Kavetski, D., Pfister, L., Hoffmann, L., Savenije, H. H. G., \& McDonnell, J. J. (2010). Assessing the impact of mixing assumptions on the estimation of streamwater mean residence time. Hydrological Processes, 24(12), 1730?1741. Retrieved from http://doi.org/10.1002/hyp.7595

Fiedler, M. (1973). Algebraic connectivity of graphs. Czechoslovak mathematical journal, 23(2), 298-305.

Gabrielli, C. P., Morgenstern, U., Stewart, M. K., \& Mcdonnell, J. J. (2018). Contrasting groundwater and streamflow ages at the maimai watershed. Water Resources Research, 54(6), 3937-3957. Retrieved from http://doi.org/ 10.1029/2017WR021825

Gilbert, D., \& Heiner, M. (2006). From petri nets to differential equations - an integrative approach for biochemical network analysis. In S. Donatelli \& P. S. Thiagarajan (Eds.), Proc. icatpn 2006 (p. 181-200). Springer.

Haas, P. J. (2006). Stochastic petri nets: Modelling, stability, simulation. Springer Science \& Business Media.

Haynes, G., \& Hermes, H. (1970). Nonlinear controllability via lie theory. SIAM J. Control, 8, 450460 .

Herajy, M., \& Heiner, M. (2015). Modeling and simulation of multi-scale environmental systems with generalized hybrid petri nets. Frontiers in Environmental Sciences - Methods, 3, 53, 1-14. Retrieved from doi:10.3389/fenvs.2015 .00053

Hermann, R., \& Krener, A. (1977). Non linear controllability and osservability. IEEE Trans. Automat.Contr., 22, 728740.

Hrachowitz, M., Savenije, H., Bogaard, T., Soulsby, C., \& Tetzlaff, D. (2013). What can flux tracking teach us about water age distribution patterns and their temporal dynamics? Hydrology and Earth System Sciences, 17 (2), 2013.

Jensen, K., \& Kristensen, L. M. (2009). Coloured petri nets: modelling and validation of concurrent systems. Springer Science \& Business Media.

Kaiser, D. (2005). Physics and feynman's diagrams. American Scientist, 93, 156,165 .

Kalilath, T. (1980). Linear systems. Prentice-Hall.

Kalman, R. (1959). On the general theory of control systems. IRE Transactions on Automatic Control, 4(3), 481-493.

Kampf, S., \& Burges, S. (2007). A framework for classifying and comparing distributed hillslope and catchment hydrologic models. Water Resources Research, 43(5), 1-24. Retrieved from http://doi.org/10.1029/2006WR005370

Kirchner, J. (2016). Aggregation in environmental systems -part2: Catchment mean transit times and young water fractions under hydrologic nonstationarity. $H y$ drology and Earth System Sciences, 20(1), 299-328. Retrieved from http:// doi.org/10.5194/hess-20-299-2016

Knoben, W. J. M., Freer, J., Fowler, K. J. A., Peel, M. C., \& Woods, R. A. (2019). Modular assessment of rainfall-runoff models toolbox (marrmot) v1.0: an open source, extendable framework providing implementations of 46 conceptual hydrologic models as a ontinuous space-state formulations. Geoscientific Model DEvelopment Discussion, 1-26. Retrieved from http://doi.org/10.5281/zenodo. 2482542

Koch, I. (2010). Petri nets-a mathematical formalism to analyze chemical reaction networks. Molecular Informatics, 29(12), 838-843.

Koch, I., Reisig, W., \& Schreiber, F. (2010). Modeling in systems biology: the petri net approach (Vol. 16). Springer Science \& Business Media.

Kuppel, S., Tetzlaff, D., Maneta, M. P., \& Soulsby, C. (2018). What can we learn from multi-data calibration of a process-based ecohydrological model? Envi- 
ronmental Modelling \& Software, 101, 301-316.

Liu, Y.-Y., \& Barabasi, A.-L. (2016). Control principles of complex systems. Reviews of Modern Physics, 88(3), 247-258. Retrieved from http://doi.org/10 $.1103 /$ RevModPhys . 88.035006

Lohn, J. D., \& Colombano, S. P. (1999). A circuit representation technique for automated circuit design. IEEE Transactions on Evolutionary Computation, 3(3), 205-219.

Luenberger, D. (1979). Introduction to dynamic systems. John Wiley \& Sons, Inc.

Marsan, M. A., Balbo, G., Conte, G., Donatelli, S., \& Franceschinis, G. (1994) Modelling with generalized stochastic petri nets. John Wiley \& Sons, Inc.

Merlin, P., \& Farber, D. (1976). Recoverability of communication protocolsimplications of a theoretical study. IEEE transactions on Communications, $24(9), 1036-1043$.

Montaldo, N., Rondena, R., Albertson, J., \& Mancini, M. (2005). Parsimonious modeling of vegetation dynamics for ecohydrologic studies of water- limited ecosystems. Water Resources Research, 41(10), W10416. Retrieved from http://doi.org/10.1029/2005WR004094

Murata, T. (1989). Petri nets: Properties, analysis and applications. Proceedings of the IEEE, 77(4), 541-580.

Navarro-Gutiérrez, M., Ramírez-Treviño, A., \& Gómez-Gutiérrez, D. (2013). Modelling the behaviour of a class of dynamical systems with continuous petri nets. In Emerging technologies \& factory automation (etfa), 2013 ieee 18th conference on (pp. 1-6).

Oster, G., Perelson, A., \& Katchalsky, A. (1971). Network thermodynamics. Nature, 234, 393-399.

Patten, B., Higashi, M., \& Burns, T. (1990). Trophic dynamics in ecosystem networks: significance of cycles and storage. Ecological Modelling, 51, 1-28. Retrieved from https://doi.org/10.1016/0304-3800(90)90055-L

Petri, C. (1966). Communication with automata (Unpublished doctoral dissertation). University of Bonn.

Ramchandani, C. (1974). Analysis of asynchronous concurrent systems by petri nets (Tech. Rep.). Massachusetts Inst. of Tech Cambridge project MAC.

Savenije, H. G., \& Hrachowitz, M. (2017). Hess opinions catchments as metaorganisms a new blueprint for hydrological modelling. Hydrology and Earth System Science, 21, 1107-1116. Retrieved from https://www.hydrol-earth -syst-sci.net/21/1107/2017/hess-21-1107-2017.html

Savenije, H. H. G., \& Hrachowitz, M. (2017). Catchments as meta-organism a new blueprint for hydrological modelling. Hydrology and Earth System Sciences, 21(2), 1107-1116. Retrieved from http://doi.org/10.5194/ hess-21-1107-2017

Seibert, J., \& Vis, M. (2012). Teaching hydrological modeling with a user-friendly catchment-runoff-model software package. Hydrology and Earth System Sciences, $16(9), 3315$.

Silva, M., \& Recalde, L. (2004). On fluidification of petri nets: from discrete to hybrid and continuous models. Annual Reviews in Control, 28(2), 253-266.

Singh, V. P., \& Woolhiser, D. A. (2002). Mathematical modeling of watershed hydrology. Journal of Hydrology, 7, 270-292.

Sontag, E. (1998). Mathematical control theory: deterministic finite dimensional systems. Springer-Verlag.

Soulsby, C., Birkel, C., \& Tetzlaff, D. (2016). Modelling storage-driven connectivity between landscapes and riverscapes: towards a simple framework for long-term ecohydrological assessment. Hydrological Processes, 30(14), 2482-2497.

Strogatz, S. (1994). Non linear dynamics and chaos, with application to physics, biology, chemistry and engineering. Perseus Books. 
Takahashi, Y. (2005). Translation from natural language to stock flow diagrams. In Proceedings of 23rd international conference of system dynamics society.

Todini, E. (1988). Rainfall runoff modelling: Past, present and future. Journal of Hydrology, 100, 341352.

Wagener, T., Wheater, H., \& Gupta, H. (2004). Rainfall-runoff modelling in gauged and ungauged catchments. Imperial College Press.

Wilkinson, D. J. (2011). Stochastic modelling for systems biology. CRC press.

Willems, J. (2007). The behavioral approach to open and interconnected systems. IEEE Control Systems Magazine, December, 46-99. Retrieved from http:// doi.org/10.1109/MCS.2007.906923

Yamada, T., \& Foulds, L. R. (1990). A graphtheoretic approach to investigate structural and qualitative properties of systems: A survey. Networks, 20, 427.

Zehe, E., Ehret, U., Pfister, L., Blume, T., Schrder, B., Westhoff, M., ... Kleidon, A. (2014). From response units to functional units: a thermodynamic reinterpretation of the hru concept to link spatial organization and functioning of intermediate scale catchments. Hydrology and Earth System Sciences, 18, 4635-4655. Retrieved from http://doi.org/10.5194/hess-18-4635-2014 